\title{
Mitosis and DNA Replication and Life Origination Hydrate Hypotheses: Common Physical and Chemical Grounds
}

\author{
Ostrovskii Victor E. ${ }^{1}$ and Kadyshevich Elena A. ${ }^{2}$ \\ ${ }^{1}$ Karpov Institute of Physical Chemistry, Moscow, \\ ${ }^{2}$ Obukhov Institute of Atmospheric Physics RAS, Moscow, \\ Russia
}

\section{Introduction}

\subsection{Formulation of the problem under consideration}

We proceed from the assumptions that the Earth's living matter had originated on our planet from inorganic and simplest organic substances as an inevitable product of the atomistic world and that the same natural phenomenon underlies the processes of origination and reproduction of living matter. We believe that living matter was originating multiply and, maybe, originates now and that the diversity of the available forms of living matter is caused mainly by some variations in parameters of the native medium. In all probability, stable undisturbed conditions favor origination of the simplest living matter and this process proceeds so slowly that its direction is thermodynamically favorable. "Nature makes no jumps" (Nature non facit saltus (Lat.)): we had this Latin aphorism at our hearts when thinking over the problems of this paper.

The occurrence and reproduction of nucleic acids (deoxyribonucleic acid (DNA) and ribonucleic acid (RNA)) is the principal feature of living matter. Their molecules represent alternating phosphate-sugar chains, in which a hydroxyl of each sugar group is substituted with a so-called nitrogen base (N-base). As sugars, deoxy-D-riboses (DDR) and D-riboses (DR) enter the molecules of DNA and RNA, respectively. As N-bases, pyrimidines (cytosine $(\mathrm{Cy})$, thymine (Th), and uracil (U)) and purines (guanine $(\mathrm{G})$ and adenine (Ad) and, more rarely, xantine $(\mathrm{X})$, hypoxantine $(\mathrm{Hx})$ ) and some quite rare $\mathrm{N}$-bases are known. DNA molecules contain no U, and RNA molecules contain no Th. In the living organisms, DNA molecules are, at least most of the time, in the state of dimers, termed double helixes. The spatial arrangement of different components in the molecules of nucleic acids is strictly defined. For each organism, the occurrence of DNA molecules of a definite composition is the characteristic feature. It is commonly accepted that the heritage of living organisms is determined by the sequence of the N-bases in the DNA molecules.

The interest of the scientific community to the problem of the mechanism of living matter origination from mineral substances was triggered by the first-ever naturalistic hypothesis announced by A. Oparin (1924). It was twenty years before clarification of the facts that nucleic acids rather than proteins cause the diversity of living organisms and regulate their development. Oparin's hypothesis became the starting point for numerous works dedicated 
to this intriguing problem. With time, this problem was divided into two sub-problems: where did living matter originate, at the Earth or anywhere in the Universe beyond our planet, and how, i.e., by what mechanism, did it originate? We leave the first sub-problem out of our consideration and discuss the living matter origination mechanism, which can be applied, in our opinion, to any Universe region, where the appropriate conditions exist. Some authors think fit to regard imaginary processes of extended reproduction of some substances containing no nucleic acids or containing some of their surrogates that include silicon or other chemical elements, instead of carbon, as life. We risk of sounding tiresome and cold-blooded, but we believe that no other form of life but that similar to the Earth's one is possible and the other above-mentioned concepts have no scientific ground.

What is the physicochemical mechanism of cell replication? This is one of the central problems of our consideration. But is such a statement of the problem promising? May it be that none general physicochemical mechanism for the phenomenon of multi-step selfreproduction of a cell exists and each step is controlled by some different specific articles termed ferments, thousands of which are synthesized at right moments and carried to some definite points by some miraculous mode, following the plan once written independently of the physical and chemical laws? Who is the author of this plan? Is it the knowable Nature or a mysterious and unknowable Force that stays out of the natural laws and over them?

If this is Nature, all its manifestations are regulated by a rather limited number of physicochemical laws, which, taking a joint action on a cell located in a medium of any definite composition, temperature, and other ambient conditions, lead this cell to its inevitable replication, which may be precluded only by a critical variation in the conditions and (or) chemical composition of the medium. What is the key natural phenomenon that underlies the life-cycle repetition for any element of living matter termed cell? The answer for this question is just the aim to which we aspire. Nature is simple and, therefore, among the laws that determine running of any natural process, a leading one is usually specifiable. It is our opinion that the simplicity intrinsic to a natural phenomenon may be latent for the time being but is the reality noted by I. Newton (Newton, 1687), who wrote that "...Nature does nothing in vain, and more is in vain, when less will serve; for Nature is pleased with simplicity, and affects not the pomp of superfluous causes", i.e., it is simple and doesn't luxuriate in excessive sources. We are of the opinion that the most concise hypothetical way assumed to be the natural one gives the hypothesis the best chance to be correct. Indeed, most physicists believe that the hypothesis more laconic in its assumed steps and included substances is preferable against more complicated hypotheses, similarly to chess players who believe that the less is the number of pieces included into a chess problem, the more perfect it is. However, some researchers think otherwise. For example, Galimov argues that "...despite the remarkable inventiveness of nature in creating intricate biological mechanisms, their analysis indicates that almost each given result could be achieved by a simpler means" (Galimov, 2001, p. 218). He "forces" Nature, according to his hypothesis (Galimov, 2009), to create first adenosine triphosphate through a very multiple synthesis and to use it then for creation of living articles through no less multiple chain of syntheses. If the today Nature has the "know how" allowing for creation living articles time and again, it should formerly perform the procedure of creation of the first living articles from mineral substances and this original procedure should be similar to that being repeated in our days. For a long time, this procedure could vary adapting itself to the environments but its principle law-obedience should be apparently conserved in time. Thus, the solutions of these two puzzles of Nature are interconnected. 
Therefore, a revelation of the key phenomenon and leading law that determine events of living matter origination would approach us closely to a solution of the problem of cellular replication and, vice versa, a solution of the problem of cellular replication could supply us almost certainly with a magic wand capable of helping in clarification of the problem of living matter origination. We try to reveal the key physicochemical phenomenon and the leading natural law that determine both these problems and, on this basis, to describe the hypothetical mechanisms of living matter origination (the Life Origination Hydrate Hypothesis (the LOH-hypothesis)) and of cellular replication (the Mitosis and Replication Hydrate Hypothesis (the MRH-hypothesis)).

We develop the OK-hypothesis of the Universe development for the period from the Supernova explosion to the cellular living matter origination (OK is the abbreviation of the family names of the authors). This hypothesis includes the Solar System formation hypothesis (PFO-CFO hypothesis) (Ostrovskii \& Kadyshevich, 2008, 2009a, 2009b, 2011; Kadyshevich \& Ostrovskii, 2010a, 2010b; Kadyshevich, 2009a, 2009b), the hypothesis of formation of natural gas and some other localizations of minerals (Ostrovskii \& Kadyshevich, 2007, 2008; Ostrovskii, 2010), and the LOH-hypothesis (Ostrovskii \& Kadyshevich, 2000, 2002, 2006, 2007, 2009c, 2010; Kadyshevich \& Ostrovskii, 2009, 2010c, 2010d; Kadyshevich, 2007) and the MRHhypothesis (Kadyshevich \& Ostrovskii, 2007; Kadyshevich, 2006).

The OK-hypothesis as a whole and each of its components taken separately are based on the notion that all natural phenomena proceed as a result of regular and inevitable chemical transformations regulated by universal physical and chemical laws. When reconstructing Nature's way, we are governed by the following main principles: (1) The Newton principle of simplicity. (2) The principle of repetition of supposed events and of the presence of individual features in the reproduced events. The matter is that, in Nature, there are many similar but somewhat differing events and there are no unique events without close analogues. (3) The principle of the unity of the event point. Separation of an event into several sub-events proceeding in different points with the subsequent interaction between the sub-events decreases the probability of the resulted event, because it multiply decreases the degree of repetition of the event as a whole.

\subsection{Introduction into the life origination hydrate hypothesis}

The processes that gave rise to life could not obey biological laws because they proceeded in the absence of biota. Hence, the origin of life is first and foremost a problem of chemistry and physics and a number of related scientific disciplines concerned with mechanisms underlying the development of the atomistic world.

Vitaly Ginzburg, who was awarded with the 2003 Nobel Prize, described the problem of the "reduction of the animate to the inanimate" in his Nobel lecture (Ginzburg, 2004) as one of the three great physical problems facing the 21st century. He formulated this thought in the following words (Ginzburg, 1999): “At present, we believe that we know what all alive consists of, meaning electrons, atoms, and molecules. We are aware of the structure of atoms and molecules and of the laws governing atoms, molecules, and radiation. Therefore, the hypothesis of reduction, i.e., the possibility of explaining the life on the basis of physics, of the already known physics, is natural. The main problems are those of the origin of life and of the appearance of consciousness (mentality). The problem is not solved, and I am inclined to think that it will be unreservedly solved only after 'life in a test-tube' is created."

We propose an original solution to the problem of the origin of living-matter simplest elements (LMSEs), i.e., N-bases and riboses, and of nucleic acids that ensure the protein 
synthesis and transmission of major traits of living organisms from one generation to another. Immanuel Kant contended that "To get knowledge from nature, the Mind should address to it, on the one hand, with his own principles, which are necessary for concordant phenomena to carry the force of law, and, on the other hand, with experiments intended in conformity with these principles." (Kant, 1997, pp. 85, 86). With this in mind, we described an experiment that could be used to verify our hypothesis if it is reproduced by several laboratories in a coordinated manner with the experimental conditions varied within a certain range (Ostrovskii \& Kadyshevich, 2006, 2007). If the hypothesis proves valid, this experiment may yield precursors of nucleic acids and, possibly, DNA-like molecules. It can be expected that the LOH-hypothesis will contribute to realization of the cautious prediction by Ginzburg, who noted that he "would not be surprised if 'life in a test tube' would be created in the 21st century" (Ginzburg, 1999).

We will first clarify our understanding of the borderline between the animate and inanimate. There is no consensus with regard to this issue. Thus, Oparin believed that life development started with the appearance of nucleotide sequences (nucleic acids) when the process of chemical evolution as the struggle among protobionts was coming to an end and competition in the growth rate turned into the struggle for existence (Oparin, 1924, 1957). Spirin maintains that "the origin of life in its present cellular form is reduced to the development of a mechanism of heritable protein synthesis" (Spirin, 2001), but leaves the problem of a cellular life beyond this definition. In the late 19th century, Friedrich Engels defined life as "the form of existence of protein bodies".

The problem of the border between the animate and inanimate is far from vain even if its discussion may seem to make no concrete sense. Drawing the line between the animate and inanimate determines the interpretation of viruses (DNA molecules containing genetic information and enclosed in a protein membrane), and viroids as subjects of biological (including biophysical) or organic and physicochemical studies. This problem has been discussed since 1935, when Stanley pioneered in isolation and crystallization of the tobacco mosaic virus. L. Pauling summarized the situation as follows: "in fact, there is no reason to consider this question as a scientific one; indeed, it reduces to the definition of the notion. If a living organism is defined as a material structure capable of self-reproduction, then plant viruses should be reckoned among living organisms. If it is assumed that living organisms must be capable of metabolism, then plant viruses must be regarded as mere molecules having a molecular weight of about 106 and a structure allowing them to catalyze, in a certain medium, a chemical reaction leading to the synthesis of molecules identical with them" (Pauling, 1970).

We emphasize that Pauling's opinion is not faultless in the light of modern knowledge. It has been many times demonstrated in the past 10 to 15 years (see, e.g., Orgel, 1992, 2000; Cech \& Bass, 1986; Li \& Nicolaou, 1994) that not only nucleic acids but even simpler organic substances are capable of self-replicating with consumption of certain chemical elements from the surrounding and excretion of nonutilized molecular residues. Should we call such a process "metabolism"? No reasoning can answer this question; the answer can be deduced only from the practice of using the term. Today, viruses and even viroids are regarded as biological substances and are studied by biologists, although a vast field of activity remains open to physicists and chemists. Each of these species contains DNA of a specific composition. In our opinion, it is therefore justified to regard the appearance of nucleic acids in the course of evolution as the onset of the simplest precellular life. Such a demarcation between the animate and inanimate is especially logical because, as noted by Kauffman, 
complex organic systems such as DNA and RNA inevitably become self-replicating and their self-replication proceeds through an autocatalytic mechanism (Kauffman, 1993). If a living system were devoid of nucleic acids, with its protein content preserved, the vital activity would surely cease; if a living system were devoid of its protein, with the nucleic acids preserved, the vital activity of the system supplied with nutrients might normalize with time.

Apparently, once nucleic acids had originated and propagated and a medium appropriate for their existence and replication had appeared, the appearance of cellular life was merely a matter of time. It follows from the foregoing that in our terminology, DNA and RNA are the simplest forms of precellular living matter, while N-bases and riboses are its simplest elements or constituents. We consider it appropriate to expound and substantiate our understanding of the border between the animate and inanimate, bearing in mind Kant's definition of physics as the theory field that should perceive natural objects by mind and that should determine them a priori and "purely, at least partially, and then should do it also on the basis of knowledge sources other than the mind" (Kant, 1997, p. 84).

Below, we briefly consider an important and rather intriguing question on dating the historic period when the first simplest living organisms appeared at the Earth. This question was recently developed as comprehensively as the today knowledge of the Archaean history of the Earth allows (Fedonkin, 2006, 2009). According to some authors (Hedges \& Kumar, 2003; Mojzsis et al., 1996), the early divergence among prokaryotes was 3970 Myr ago (molecular time) or $3800 \mathrm{Myr}$ ago (fossil time) and the origin of eukaryotes was $2730 \mathrm{Myr}$ ago (molecular time) or 2150 Myr ago (fossil time). Note that the dates of divergence among prokaryotes were recently brought into question. The matter is that this conclusion was made on the basis of indirect data on the isotopic composition of the carbon inclusions within the apatite crystals mined from the Greenland Archaean beds. Meanwhile, according to others (Fedo \& Whitehouse, 2002; van Zuilen et al, 2002), the apatite crystals and carbon inclusions could be formed much later as a result of metamorphism influenced by the hot fluids. We see that the molecular time and the fossil time differ rather significantly and that the periods of the starts of the Earth prokaryotization and eukaryotization are known rather approximately. These conclusions relate not only to the prokaryotes and eukaryotes ages. Fossil time measurements led to the conclusion that the earliest localities of invertebrate animals lived 600-550 Myr ago and that most of the species of invertebrate animals occurred in Cambrian period, i.e., their age is less than 510 Myr. However, the measurements of the molecular time give a period of 1500-1200 Myr ago for the development of the first Metazoa colonies and lead to the conclusion that the main branches of the invertebrates lived many hundreds of millions of years before Cambrian (Fedonkin, 2009). These data show that the today knowledge on the positions of different events on the time-scale is rather rough. Note that, multicellular organisms apparently appeared independently in the Earth history no less than 24 times (Buss, 1987).

Giving A. Oparin his due as the world's first researcher to consider living matter objects as the ones not differing fundamentally from the lifeless matter, we should note that his hypothesis could not be correct because it rested upon a pseudo-scientific statement. He thought mistakenly that the living matter entropy is so small that no decrease in the enthalpy could make the free energy change negative in chemical transformations of mineral substances to living matter. Therefore, Oparin believed that external energy in the form of electric discharges, heat of underground thermal water sources, etc. is necessary for such transformations. In addition, he, for some reason, thought that living matter could 
originate at ground-atmosphere or water-atmosphere phase boundaries. Meanwhile, the DNA and RNA molecules are very long, the chemical elements for their formation should be chosen very selectively, the atom groups should be located in strictly determined positions and should be limited in size, and some other special requirements should be performed in the process of their formation. The complexity of these conditions suggests the idea that such molecules could originate only under condition of the absence of heat, electrical, and weather perturbations, which are most likely capable of destroying any order rather than to create and maintain it. Therefore, the conditions at phase boundaries are hardly suited for origination of nucleic acids, which are necessary for subsequent formation of living matter. The Miller-Urey experiments showed that mineral substances could produce some amino-acids under the conditions that can be considered as those approached to the conditions of the Earth's primordial atmosphere, but nothing was synthesized that would be suitable for the subsequent RNA and DNA formation. Productions of DNA and RNA molecules from simple mineral substances by Oparin's mechanism represent extremely low-probability events, which cannot be realized in practice. In addition, this hypothesis gave no realistic assumption on a possible cause of the phenomenon of monochirality of biologically active substances.

Meanwhile, Russian physicist and biologist L. Blyumenfeld calculated the living matter entropy on the basis of the simple generalized approach of statistical physics and came to the unambiguous conclusion that "... according to physical criteria, any biological system is ordered no more than a rock piece of the same weight" (Blyumenfeld, 1981, 1996, 2002). Somewhat later, the standard values of the enthalpy of formation $\left(\Delta_{\mathrm{r}} \mathrm{H}^{0}\right)$ and of the entropy $\left(\mathrm{S}^{0}\right)$ were obtained experimentally for different biologically active substances (Alberty, 2003; Ould-Moulaye et al., 2001; Lide, 1996; Boerio-Goates, 2005). We calculated the standard $\left(\Delta_{\mathrm{i}} \mathrm{G}^{0}\right)$ values for a number of reactions leading to formation of nitrogen bases and riboses from minerals (Ostrovskii \& Kadyshevich, 2006, 2007). It was stated that no external energy is necessary to synthesize biologically active substances from minerals, because the freeenergy changes in such reactions are negative and rather great in magnitude. Unfortunately, the mistaken opinion by Oparin on the necessity of an external energy for origination of living matter from minerals is distributed among the researchers who try to understand the natural way from minerals to living matter, and several hypotheses that include this opinion in an explicit or implicit form are available.

The life origination hypotheses developed by Oparin and his followers are also criticized from another standpoint (Shapiro, 2000). Shapiro believes that the production of an information-bearing homopolymer within a complex mixture by chance cannot be excluded, but if such an event was required to start life, then its origin would have been an extremely improbable accident, and prospects for life elsewhere would be diminished. According to his opinion, "...a more likely alternative for the origin of life is one in which a collection of small organic molecules multiply their numbers through catalyzed reaction cycles, driven by a flow of available free energy" (Shapiro, 2006). More or less similar views on the life origination problem are available in the literature (e.g., Deamer, 1997; Segré et al. 1998; Parmon, 1999).

When considering the processes of metabolism of prokaryotes and eukaryotes, we try to reveal the central common natural physicochemical phenomenon underlying division of prokaryotic and somatic eukaryotic cells. Following Oparin, we consider living organisms as systems not differing fundamentally from the lifeless matter; i.e., we take that the intracellular processes are controlled by the universal physical and chemical laws. We 
proceed from the assumption that eukaryotic mitosis (Alberts et al., 2002 (Ch.4); Lodish et al., 2000 (Ch. 13) and prokaryotic binary fission (Alberts et al., 2002 (Ch.4); Lodish et al., 2000 (Ch. 12) are connected with the same definite fundamental natural physicochemical phenomenon that has them "in tow". In other words, the same physicochemical phenomenon is the prime cause of the eukaryotic mitosis and prokaryotic binary fission. Otherwise, we should evidently take that the first prokaryotes and the first eukaryotes had originated in nature independently and their subsequent metabolisms and evolutions were controlled by different physical and chemical regularities. In this case, these two branches of living matter should be, most likely, incompatible in their vital functions. Meanwhile, living organisms belonging to numerous species characterized by the anatomies and physiologies that are intermediate between those inherent in typical prokaryotes and eukaryotes are common in nature. This reasoning gives an indirect confirmation for our assumption on the similarity of the prime physicochemical causes underlying the mitosis and binary fission. We see additional confirmation for this assumption in the following fundamental common features of the anatomies and metabolisms of prokaryotes and eukaryotes. First, prokaryotes and eukaryotes transmit their principal hereditary characters from generation to generation through DNA molecules, which are similar in their chemical composition and molecular structure. Second, the eukaryotic mitosis and prokaryotic binary fission are principally similar in their results. Namely, either of them results in separation of genome into two identical halves and in subsequent cytokinesis leading to division of the cytoplasm and cell membrane into two identical new cells. Third, both the eukaryotic mitosis and prokaryotic binary fission are preceded by the DNA replication processes similar in their principal results. The MRH-hypothesis developed by us contains the supposition that formation of new nuclear envelopes and of cell membranes between two newly-formed cells in the processes of mitosis and cytokinesis is provided by precipitation of complex organomineral substances from oversaturated solutions. However, the central phenomenon providing the existence of living matter is not mitosis as such, but transmission of duplicated genomic information from parental genomes to daughter ones, i.e., the DNA replication. We suppose that DNA replication is initiated by the neutralization of the amideamide interactions in DNA double helixes by water dipoles. Thus, two familiar and commonly-known natural phenomena (precipitation from oversaturated solutions and neutralization of the DNA-DNA dipole interactions by water dipoles) summarized with the phenomenon of continuous diffusion of water and organics into living cells from the outside represent the basis for the phenomenological content of living-matter reproduction.

However, each of these three phenomena proceeds monotonously in time and, therefore, the last statement as such is only a declaration that does not clarify metabolic processes. This paper represents an attempt to reveal the mechanisms of transformation of these monotonous processes into the cyclic ones providing development of living matter, including mitosis and DNA replication. We try to show that the so-called genetic code is nothing but manifestation of the universal physical and chemical laws guiding the chemical transformations in aqueous media containing organo-mineral substances of definite chemical compositions. We by no means take into account all factors influencing the processes under consideration but try to reveal the core phenomena controlling the directions of these processes. Finishing the introduction to this paper, we would like to say that the occurrence of individual organelles inside living cells is not necessarily caused by the usefulness of all these niceties for the metabolic processes. The occurrence of some of them might be caused by the natural processes of precipitation of one or another organic 
crystal structure from the saturated solution, and their disappearance in the course of mitosis or replication might be associated with swelling or dissolving caused by the concentration variations within the cell. The complexity of the structures of intracellular organelles and the repetition of the structures from cycle to cycle by no means contradict this opinion. Indeed, now that a lot of supramolecular crystals are synthesized artificially, we know well how daedal and fantastical the forms of precipitated crystal organics can be. Note that some organelles, such as chloroplasts and mitochondria (Henze \& Martin, 2003) in eukaryotic plant and animal cells, have their own DNA and, evidently, use the intracellular medium just as the corresponding eukaryotic plant and animal cells use their environment.

\section{The gas-hydrate matrix as the medium for living- matter origination and reproduction}

\subsection{Gas hydrates as a class of chemical substances}

Gas-hydrates (Byk \& Fomina, 1970; Atwood et al., 1996; Carroll, 2003; Chaplin, 2010) are honeycomb, solid or semi-liquid, mineral substances with cubic (structure I, a $=1.20 \mathrm{~nm}$ ), face-centered cubic (structure II, a $=1.73 \mathrm{~nm}$ ), or hexagonal (structure $\mathrm{H}, \mathrm{a}=1.23 \mathrm{~nm}$ and $\mathrm{c}=$ $1.02 \mathrm{~nm}$ ) lattices composed of large and small cavities, where the waters (hosts) are the vertices of the cavities and other atoms, molecules, or atomic groups (guests) are housed within the cavities. As guests, particles of one type or two different types can be housed within the large cavities and, in addition, particles of a third type can be housed within the small cavities. Gas-hydrates that contain guest particles of two or more different chemical natures are termed mixed gas-hydrates. The structure type depends on the size of the guest particles or on the sizes of the guest particles if particles of two or three types are housed within the cavities. Gas hydrate structures can exist only under the condition that some guest particles are housed within no less than $80 \%$ of the cavities of any definite size; otherwise, the loose structure collapses and transforms to the usual dense ice. For example, in the hydrate structure II, the ideal water-to-guest ratio is equal to 17 and the critical one is equal to $20 \div 21$. In gas-hydrates, the guest $-\mathrm{H}_{2} \mathrm{O}$ interactions are provided by the Van-derWaals $(\mathrm{W}-\mathrm{d}-\mathrm{W})$ forces.

Figure 1 is designed in scale; it presents the gas-hydrate cavities of the hydrate structures I, II, and H. Structures I, II, and H contain 512 and 51262, $5^{12}$ and 64 , and 512, 435663, and $5126^{8}$ cavities, respectively (over the structures, the lower-case figures mean the numbers of the edges of a facet and the superior figures mean the numbers of such facets that terminate the corresponding cavity). In Fig. 1, each vertex responds to the $\mathrm{O}$ atom of a $\mathrm{H}_{2} \mathrm{O}$ molecule and each edge responds to the sum of the $\mathrm{O}-\mathrm{H}$ valence bond of any $\mathrm{H}_{2} \mathrm{O}$ molecule and the $\mathrm{H} \cdots . \mathrm{O}$ hydrogen bond of this $\mathrm{H}_{2} \mathrm{O}$ molecule with any adjacent $\mathrm{H}_{2} \mathrm{O}$ molecule. Each of structures I and II has cavities of two types, and structure $\mathrm{H}$ has cavities of three types. Figure 1 gives also the sizes of particles capable of being housed within cavities of different types. Gashydrates are widely distributed in nature. For example, natural methane deposits exist frequently in the form of gas hydrates.

For crystal structures I, II, and $\mathrm{H}$, the unit cell formulas, $(\mathrm{S})_{2} \cdot(\mathrm{L})_{6} \cdot 46 \mathrm{H}_{2} \mathrm{O},(\mathrm{S})_{16}(\mathrm{~L}+)_{8} \cdot 136 \mathrm{H}_{2} \mathrm{O}$, and $(\mathrm{S})_{5}(\mathrm{~L}++) \cdot 34 \mathrm{H}_{2} \mathrm{O}$, respectively, are proposed ( $\mathrm{S}$ is the small guest, $\mathrm{L}$ is the large guest, $\mathrm{L}+$ is the larger guest, and $\mathrm{L}++$ is the largest guest). Hydrate structures remain stable when the guest contents are below their stoichiometric values by $20-25 \%$. Each unit crystal cell of the structure I, II, or H contains 2 small $5^{12}$ (20 waters) and 6 large $5^{12} 6^{2}$ (24 waters) cavities, 16 small $5^{12}$ and 8 large $5^{12} 6^{4}$ (28 waters) cavities, or 3 small 512, 2 small $4^{35} 5^{6} 6^{3}$ (20 waters) and 

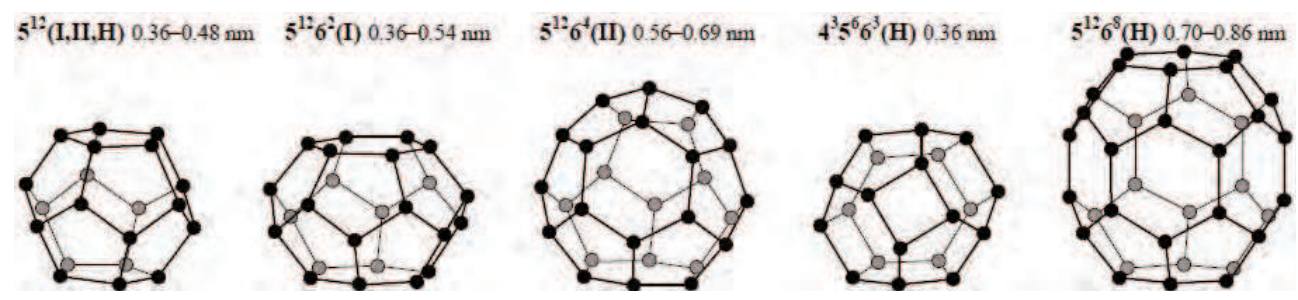

Fig. 1. Intra-structural cavities of hydrate structures I, II and H: the vertexes are the O-atoms of $\mathrm{H}_{2} \mathrm{O}$ molecules, and the length of each edge corresponds to the sum of the lengths of the $\mathrm{O}-\mathrm{H}$ valence bond in any $\mathrm{H}_{2} \mathrm{O}$ molecule and $\mathrm{H} \cdots . . \mathrm{O}$ hydrogen bond between this and an adjacent $\mathrm{H}_{2} \mathrm{O}$ molecule; above each cavity, its free diameter, the number of its facets (the superior figures) restricted with the definite number of the edges (the lower-case figures), and the indexes of the hydrate structures into which this cavity is included are given.

1 large $5^{12} 6^{8}$ (36 waters) cavities, respectively. According to Chaplin (2010), the 512, 51262, $5^{12} 6^{4}, 4^{35} 5^{6} 6^{3}$, and $5^{12} 6^{8}$ cavities are capable of housing the molecules having diameters of 0.36-0.44 (such as Ar, $\mathrm{O}_{2}, \mathrm{~N}_{2}$, and $\mathrm{CH}_{4}$ ), 0.36-0.54 (such as $\mathrm{CO}_{2}$ and $\mathrm{C}_{2} \mathrm{H}_{6}$ ), 0.56-0.62 (such as $\mathrm{C}_{3} \mathrm{H}_{8}$ and $\left(\mathrm{CH}_{3}\right)_{3} \mathrm{CH}$ ), 0.36 (such as $\mathrm{CH}_{4}$ ), and $0.70-0.86$ (such as $\left(\mathrm{CH}_{3}\right)_{3} \mathrm{CC}_{2} \mathrm{H}_{5}$ ) nm, respectively. It was shown that water solutions of cyclic organic liquids consisting of rather large molecules, such as furan $(\mathrm{CH})_{4} \mathrm{O}$ and tetrahydrofuran $\left(\mathrm{CH}_{2}\right)_{4} \mathrm{O}$, form solid hydrate structure II at temperatures below 298 K (Stackelberg \& Meuthen, 1958). Sometimes, atoms of large-sized guest molecules partake in the formation of the "walls" of the cavities (Hagan, 1962), for example, in the so-called semi-clathrate hydrates, such as hydrates of npropylamine and alkyl-amines (McMullan et al., 1967; Jordan \& Mac, 1967). Many clathrate compounds of structure II with 17 "host" waters per one "guest" molecule are well known, e.g., $\mathrm{C}_{4} \mathrm{H}_{4} \mathrm{O} \cdot 17 \mathrm{H}_{2} \mathrm{O}$ (Stackelberg \& Meuthen, 1958), $\left(\mathrm{CH}_{2}\right)_{4} \mathrm{O} \cdot 17 \mathrm{H}_{2} \mathrm{O}$ (Pinder, 1965), $\mathrm{CH}_{3} \mathrm{Cl} \cdot 17 \mathrm{H}_{2} \mathrm{O}$ (Stackelberg \& Muller, 1954), $\mathrm{C}_{3} \mathrm{H}_{6} \cdot 17 \mathrm{H}_{2} \mathrm{O}$ (Clarke et al., 1964), and so-called mixed hydrates, such as $\mathrm{C}_{3} \mathrm{H}_{8} \cdot 2 \mathrm{H}_{2} \mathrm{~S} \cdot 17 \mathrm{H}_{2} \mathrm{O}$ (Platteeuw \& Van-der-Waals, 1959), $\left(\mathrm{CH}_{2}\right)_{4} \mathrm{O} \cdot 2 \mathrm{H}_{2} \mathrm{~S} \cdot 17 \mathrm{H}_{2} \mathrm{O}$ (Pinder, 1964), $\mathrm{C}_{3} \mathrm{H}_{8} \cdot 2 \mathrm{CH}_{4} \cdot 17 \mathrm{H}_{2} \mathrm{O}$ (Van-der-Waals \& Platteeuw, 1959), etc. According to Byk \& Fomina (1970), each unit crystal cell of structure II has the size 1.74 $\mathrm{nm}$ and consists of 136 waters, which form 16 small and 8 large cavities with the free diameters 0.48 and $0.69 \mathrm{~nm}$, respectively; the small and large cavities represent somewhatdepressed penta-dodecahedron and almost spherical hexa-decahedron, respectively. Just these structural parameters were used by us for the calculations presented below. Note that the free energy inherent in different hydrate structures is almost the same, and, therefore, they can metamorphose depending on the conditions and the nature of the guest particles.

At present, there are many under-seabed methane-hydrate deposits (Ginsburg \& Soloviev, 1998). In 2004, the methane mass in the proven marine methane-hydrate deposits was estimated as $(1 \div 5) \mathrm{mln} . \mathrm{km}^{3}$ (Milkov, 2004), and this estimate grows continuously. Underground methane-hydrate deposits are also known.

Hydrate structures have a unique peculiarity. This peculiarity is caused by the fact that the structuring is provided by the weak V-d-W forces. Therefore, the molar free energies of the structured and unstructured states are rather close. As a result, variations in the relative concentrations of the components of both the host (water) and guest (substrate) can change the aggregate (structural) state of the systems. For example, when water slowly enters forcibly into an amorphous dried water-substrate system capable of structuring, a gas-hydrate structure 
arises and develops with a decrease in the free energy up to hydrate formation over the entire system; however, entering of excessive water leads to the disruption of the hydrate structure, which proceeds also with a decrease in the free energy. We will show below that this peculiarity of the gas-hydrate structures is of principal importance for the living matter origination and development; it is possible that this peculiarity is the cause of a number of derangements in the regular functioning of living cells and multi-cellular aggregates.

The capability for hydrate formation is a fundamental property of water; it can reveal itself in solid and highly-concentrated semi-liquid systems at sufficiently low temperatures and sufficiently high concentrations (or pressures) of particles of such sizes that correspond to the free sizes of the gas-hydrate cavities; the chemical nature of the guest particles is not of principal importance for the question on the possibility of hydrate formation in any substrate-water system.

\subsection{Structuring of waters in the DNAs (and RNAs) vicinities in aqueous media 2.2.1 PAA- $\mathrm{H}_{2} \mathrm{O}$ system as the model for studies of the mechanism of DNA-DNA interaction in aqueous media}

Because of great importance of clarification of the mechanism of the purine-pyrimidine bond breakage in the process of DNA replication, information on water effects on the hydrogen DNA-DNA bonds in double helixes is of particular interest. Meanwhile, clarification of this process on the basis of water sorption or desorption in the DNA- $\mathrm{H}_{2} \mathrm{O}$ system is difficult because of the occurrence of masking hydrophilic phosphate and ribose groups in the content of DNA molecules. Therefore, it is the practice to use polyacrylamide (PAA) as the model substance, because it is the polymer that contains functional groups similar to the amido-groups (AGs) of DNA. To make certain that the functional groups of PAA and DNA are similar in their chemical properties, we studied the available data on the valence angles and lengths of the valence bonds in the AGs of these two substances and made sure of their identity (Ostrovskii \& Kadyshevich, 2000). We also studied water-vapor sorption and desorption in the $\mathrm{PAA}-\mathrm{H}_{2} \mathrm{O}$ system by adsorption and microcalorimetric methods (Ostrovskii \& Tsurkova, 1997, 1998a, 1998b; Ostrovskii et al., 2000, 2001); most of the experiments were performed in undisturbed highly-concentrated semi-liquid aqueous media at about $290 \mathrm{~K}$. Each substrate-water system intended for desorption measurements was aged before the experiments up to the equilibrium for no less than a week with no agitation. For comparison, $\mathrm{H}_{2} \mathrm{O}$ sorption and desorption were also studied in the alaninewater and glycine-water systems (Kadyshevich \& Ostrovskii, 2007). The techniques and procedures of these experiments are detailed in the works cited above in this paragraph; the original FOSKA microcalorimeter is described in Ostrovskii (2002). Some results and principal schemes of the portable sorption and desorption vacuum glass apparatuses are presented in Fig. 2. As far as we know, neither the differential heats of $\mathrm{H}_{2} \mathrm{O}$ sorption nor the differential rates of $\mathrm{H}_{2} \mathrm{O}$ sorption by PAA were studied until these experiments. The measurements of the integral heats of PAA dissolution in water yield negative and very small magnitudes (Silberberg et al., 1957; Day \& Robb, 1981). In our experiments, the following specific features of $\mathrm{H}_{2} \mathrm{O}$ sorption by polymers with functional AGs were revealed. When $\mathrm{H}_{2} \mathrm{O}$ vapor contacts with PAA in air of almost $100 \%$ humidity at about $290 \mathrm{~K}$, water sorption proceeds very slowly and terminates or, at least, moderates critically at a stoichiometry of AG. $(17 \div 18) \mathrm{H}_{2} \mathrm{O}$; in desorption experiments, heightened molar differential heats of $\mathrm{H}_{2} \mathrm{O}$ sorption are obtained at this composition of the $\mathrm{PAA}-\mathrm{H}_{2} \mathrm{O}$ system (Ostrovskii \& Tsurkova, 1997, 1998a, 1998b). 
In PAA, just AGs are the centers of $\mathrm{H}_{2} \mathrm{O}$ sorption. It is obvious that some AGs of the dry polymer are inter-PAA or intra-PAA bound by pairs, forming quadrupoles (see Fig. 4d); the rest of the AGs are as dipoles. A small gain in the integral Gibbs energy during vapor sorption against the energy of vapor condensation on the surface of liquid water (the gain is small, as, under airless conditions, the polymer can be quickly dried out) is conditioned by the following causes. The dipole moment (in Debye, D) of AG is $M_{A G}=3.8 \mathrm{D}$ (Thompson \& LaPlanche, 1963), while that of a water molecule is $M_{\mathrm{W}}=1.87 \mathrm{D}$ (Pauling, 1970), so $M_{\mathrm{AG}}>$ $M_{W}$. Thus, the energy of a unit AG-AG interaction is somewhat higher than the energy of AG- $\mathrm{H}_{2} \mathrm{O}$ interaction (in Fig. 2e, the differential heats of $\mathrm{H}_{2} \mathrm{O}$ sorption are below the heat of water condensation). However, in the systems watered only slightly, localization of a water molecule in the vicinity of an AG group leads to a decrease in the water entropy as compared to that in its non-localized state and to a decrease in the Gibbs free energy change in this process to negative values. Therefore, the waters localize near the AG groups up to organization of the water continuum, i.e., the water phase. The AGs of PAA are rather large, bound to the carbon chain, and slow. Therefore, the coordination numbers of AGs is limited by steric hindrance. Furthermore, in a dry system, some AGs are not bound to any other AG. Thus, the dipole moments of AGs cannot be completely screened. As a consequence, dry PAA has some excessive energy as compared with the equilibrium energy that it would probably have after infinitely slow drying of the $\mathrm{PAA}-\mathrm{H}_{2} \mathrm{O}$ system.
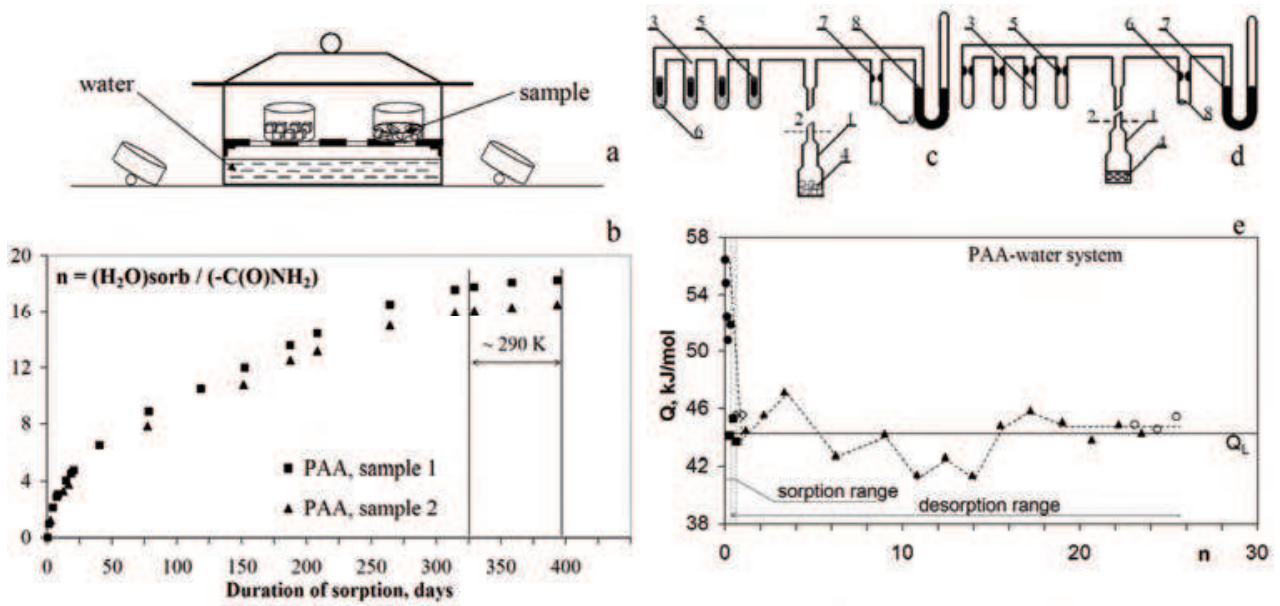

Fig. 2. (a) Water-vapor sorption by polyacrylamide (PAA) from air of $100 \%$ humidity at about $290 \mathrm{~K}$; (b) degree of PAA wetting vs. duration of sorption; (c) apparatus for sorption experiments in the deaired PAA-water system: (1) calorimetric ampoule, (2) top of the calorimeter, (3) test tube, (4) sample for wetting, (5) "breaker", (6) sealed water-containing glass sphere, (7) neck, (8) mercury manometer, and (9) tube to vacuum setup; (d) apparatus for desorption experiments: (5) neck (for other notation, see (c)); (e) calorimetric molar heats of $\mathrm{H}_{2} \mathrm{O}$ sorption: sorption by sample $8(\bullet)$ at $292 \mathrm{~K}$ and desorption from samples $7(\boldsymbol{\bullet}), 9(\boldsymbol{\Delta})$, $10(\diamond)$, and $11(\circ)$ at 292, 288, 297, and $291 \mathrm{~K}$, respectively (samples 7, 9, 10, and 11 are aged before the experiments for 14, 9, 6, and 16 days, respectively); $Q_{\mathrm{L}}$ is the heat of $\mathrm{H}_{2} \mathrm{O}$ vaporization from the pure water surface at $290 \mathrm{~K}$. 
The molar heat of water desorption (Fig. 2e) at high degrees of dilution is $n$-independent ( $n$ is the waters-to-AGs ratio in the PAA- $\mathrm{H}_{2} \mathrm{O}$ system) at $n>17$ and is equal to the tabulated value of the heat of $\mathrm{H}_{2} \mathrm{O}$ vaporization $\left(Q_{L}\right.$, horizontal line) from the pure $\mathrm{H}_{2} \mathrm{O}$ surface. The peculiarities are observable at $0<n<17$. These peculiarities reflect the complicated transformations that proceed in the hydrate phase and are not caused by experimental inaccuracies. The last statement is confirmed by the low data spread in 7 experiments performed at high $n$ values and by their close fit with the tabulated value of the heat of $\mathrm{H}_{2} \mathrm{O}$ vaporization; it is well known that hydrates can have different stoichiometry depending on the $\mathrm{H}_{2} \mathrm{O}$ content and that their different forms can somewhat differ one from another by the enthalpy and entropy.

At the initial step of wetting of dry PAA, waters diffuse into the PAA mass and interact with unpaired AGs. Therefore, the initial differential heats of water-vapor sorption are heightened. In our experiments, the heightened heats were observed up to $n \approx 0.4$; this value should depend on the degree of drying and on the rate of dehydration of the polymer.

Apparently, linearization of the polymer molecules, breaking of the irregular intramolecular and intermolecular AG-AG interactions, intramolecular structuring of each PAA molecule, and intermolecular structuring of the molecules 'filled' with water proceed as a result of the further water-vapor sorption. Note that straightening of the polymer globules in concentrated solutions of polymers with reorientation of the molecules and formation of aggregates or bundles, which contain polymer molecules packed parallel or almost parallel to each other, has been previously described (Kargin, 1962; Flory, 1962); such aggregates are considered as the germs of crystal phases. Figure 3 allows understanding a possible way to formation of the intermediate clathrate-like hydrate structure. This figure corresponds to $n=2$.

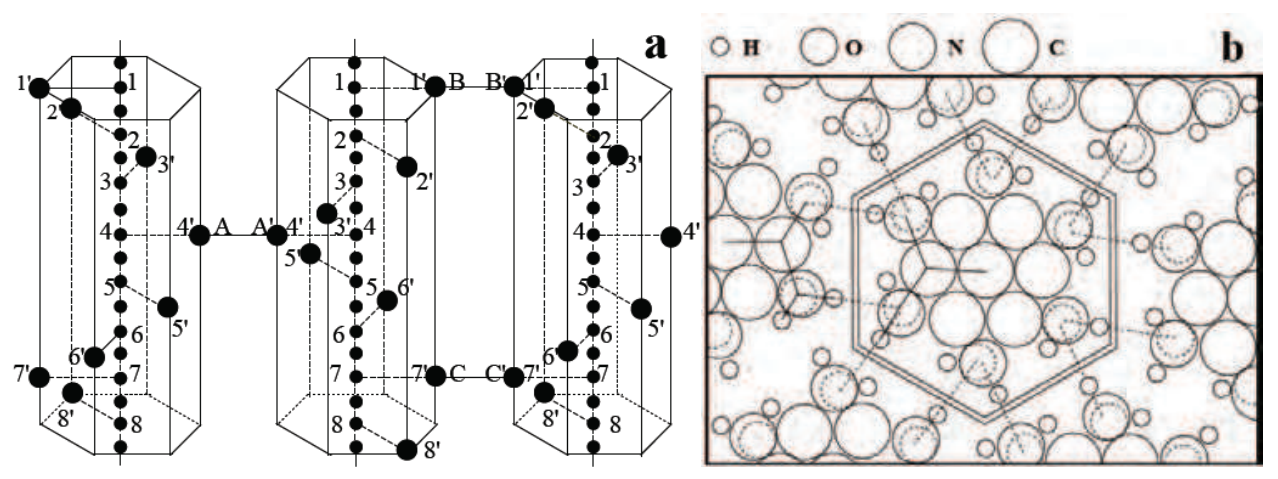

Fig. 3. Presumed intermediate clathrate-like structure for PAA. $2 \mathrm{H}_{2} \mathrm{O}$.

(a) Longitudinal section: vertical rows of numerals denote the tertiary $\mathrm{C}$-atoms of the main chains of the PAA molecules; primed numerals denote the centers of the AGs; AA', BB', and CC' segments denote the AG-AG bonds.

(b) Cross-section: double line restricts the area of the cross-section for a PAA molecule; dashed lines denote hydrogen $\mathrm{O} \cdots . \mathrm{H}-\mathrm{N}$ bonds binding the central PAA molecule with the neighboring ones; solid lines denote an example of $\mathrm{H}$-binding of two neighboring AGs of the adjacent PAA molecules. 
At the next step of water-vapor sorption, $\mathrm{H}_{2} \mathrm{O}$ sorption occurs around each AG; therewith, the AG-AG bonds weaken and the $\mathrm{AG}-\mathrm{H}_{2} \mathrm{O}$ bonds harden gradually. In this period, the difference between the differential molar heat of $\mathrm{H}_{2} \mathrm{O}$ vapor sorption in the $\mathrm{PAA}-\mathrm{H}_{2} \mathrm{O}$ system and the molar heat of water vapor condensation at the pure-water surface is determined by the difference between the molar heat consumption, which decreases with the degree of watering (because the AG-AG bonds become weaker with the degree of watering), and the molar heat liberation, which varies with the degree of watering following an unknown law. In Fig. 2e, it is seen that the differential heat of $\mathrm{H}_{2} \mathrm{O}$ vapor sorption varies in a complicated way near the heat of water condensation and becomes equal to the heat of condensation at $n>(17 \div 18)$. This $n$ value corresponds to the formation of hydrate structure II.

Figure $2 \mathrm{~b}$ shows that water-vapor sorption from the air of almost $100 \%$ humidity terminates or, at least, moderates critically at the same $n$ value, $n \approx 18$. It is seen that this result was reproduced with two PAA samples. The procedure of this experiment is simple; it is illustrated by Fig. 2a. Similar experiments showed that the approximately constant rates of $\mathrm{H}_{2} \mathrm{O}$-vapor sorption by glycine and alanine measured under the same conditions decreased by a factor of several units after $n \approx 20$ (Kadyshevich \& Ostrovskii, 2007).

The results presented in this section, apparently, give grounds for the following conclusions. At the temperature about $290 \mathrm{~K}$, at which the above described measurements were performed, PAA tends to hydrate formation in highly-concentrated semi-liquid aqueous systems. Specific $\mathrm{H}_{2} \mathrm{O}$ sorption proceeds up to a water content of $17 \div 18 \mathrm{H}_{2} \mathrm{O}$ molecules per one AG. Only after achievement of such a composition of the system, water sorbs with the molar heat effect equal to the heat of $\mathrm{H}_{2} \mathrm{O}$ condensation at the surface of pure water.

An analogous but less pronounced phenomenon is observable at water-vapor sorption by amino-acids. Most likely, the phenomenon of formation of hydrate structures around functional groups of monomers and around such molecules as amino-acids and other biologically important molecules in highly concentrated semi-liquid aqueous systems is more pronounced at lower temperatures. Unfortunately, such systems are difficult-to-study because of low rate of usual chemical processes at lower temperatures. However, the smallness of the rate doesn't stay in the way of a number of natural processes; moreover, the smallness of the rates creates the conditions when the processes could proceed selectively from one product to another and could strictly follow the sequence of gradual decreasing in the free energy of the reacting system from step to step.

\subsubsection{The $\mathrm{H}_{2} \mathrm{O}$ content in sperm as a criterion of structuring in DNA- $\mathrm{H}_{2} \mathrm{O}$ systems}

According to Josse et al. (1961), at 92\% humidity, the DNA sample contained 147 parts of $\mathrm{H}_{2} \mathrm{O}$ per 100 parts of DNA (the same data are given by others (Feughelman et al., 1955; Wilkins, 1961)). This content corresponds to $101 \mathrm{H}_{2} \mathrm{O}$ molecules per DNA fragment of composition $\mathrm{C}_{39} \mathrm{~N}_{15} \mathrm{O}_{24} \mathrm{P}_{4} \mathrm{H}_{49}$, which weigh $0.20516 \times 10^{-20} \mathrm{~g}$ and contain two pairs of deoxyribose-phosphate groups and two pairs of H-bound bases (Th-Ad and Cy-G). However, there is no evidence that the $\mathrm{H}_{2} \mathrm{O}$-to-DNA ratio (Josse et al., 1961) corresponds to the equilibrium value; in addition, it is evident that the environmental humidity in vivo is close to $100 \%$, and, thus, the $\mathrm{H}_{2} \mathrm{O}$ content in DNA must be significantly higher than that in Wilkins (1961). Nevertheless, even the $\mathrm{H}_{2} \mathrm{O}$ content of DNA samples reported by Wilkins (1961) contradicts the assumption that the equilibrium DNA structure in vivo is described by the Watson-Crick model (W-C model). Indeed, as shown below, the size of structural voids 
in the $\mathrm{W}-\mathrm{C}$ model is too small to accommodate the above-mentioned water amount. According to the $\mathrm{W}-\mathrm{C}$ model, the volume of the above mentioned DNA fragment is equal to $0.68 \cdot(1.29)^{2}=3.555 \mathrm{~nm}^{3}$. The value $1.29 \mathrm{~nm}$ is the radius of the cylinder occupied by a double helix within the sample and is equal to the sum of the half-distance between the P atoms $(1.0$ $\mathrm{nm}), \mathrm{P}-\mathrm{O}$ distance $(0.154 \mathrm{~nm})$, and the $\mathrm{V}-\mathrm{d}-\mathrm{W}$ radius of the $\mathrm{O}$-atom $(0.136 \mathrm{~nm})$. The $0.68 \mathrm{~nm}$ is twice the distance between the $\mathrm{N}$-bases. A void of volume of $3.555 \mathrm{~nm}^{3}$ can accommodate only $118.8 \mathrm{H}_{2} \mathrm{O}$ molecules at a density of $1.0 \mathrm{~g} / \mathrm{cm}^{3}$. Actually, most of this void is occupied by the 131 atoms of the $\mathrm{C}_{39} \mathrm{~N}_{15} \mathrm{O}_{24} \mathrm{P}_{4} \mathrm{H}_{49}$ fragment of DNA. Therefore, the maximum $\mathrm{H}_{2} \mathrm{O}$ content in the DNA fragment under consideration is much lower than 101 molecules. This means that, in order to accommodate the number of molecules that corresponds to the density measured by Josse et al. (1961), DNA must be packed more loosely than the W-C model predicts.

The point is that, the data on the parameters of the inter-molecular Cy-G and Th-Ad Hbinding are based on the XRD studies of samples of crystal DNA (Arnott et al., 1965). It is common practice to apply such data for characterization of the DNA in vivo, although the validity of their extension to the equilibrium DNA state in the aqueous solutions is under question. This fact is important because the DNA molecule as a whole and its individual functional groups undoubtedly have a high affinity to water. According to Wilkins (1961), the procedure applied to the preparation of the samples studied in Arnott et al. (1965) by XRD provided $95-100 \%$ humidity. However, there is no direct evidence that the equilibrium was established before these measurements and was not violated during their performance. For example, in Josse et al. (1961), there is no evidence of the absence of $\mathrm{H}_{2} \mathrm{O}$ desorption from sperm samples during their preparation and XRD measurements.

Meanwhile, our experiments (Ostrovskii \& Tsurkova, 1997, 1998a, 1998b; Ostrovskii et al., 2000,2001 ) with the PAA- $\mathrm{H}_{2} \mathrm{O}$ system led us to the following conclusions. The approach of the system to the equilibrium is very slow: within 30 days, a sample of dry polymer sorbs only one-third of the equilibrium $\mathrm{H}_{2} \mathrm{O}$ amount; the establishment of the complete equilibrium takes about a year. On the other hand, $\mathrm{H}_{2} \mathrm{O}$ desorbed intensely from the equilibrium system when the atmospheric humidity decreased or when the system was heated by 1-2 K. Meanwhile, water influences significantly the structural parameters; according to Wilkins et al. (1953) and Wilkins (1961), the helix axis length per pair of Nbases increases with wetting from $0.255 \mathrm{~nm}$ in the A-form to $0.34 \mathrm{~nm}$ in the B-form. As was noted (Josse et al., 1961), the $\mathrm{H}_{2} \mathrm{O}$ amounts in the DNA and nucleoprotein samples are not in agreement with the structure proposed. At a relative humidity of $92 \%$, the densities of nucleic acid and nucleoprotein lie between 1.34 and $1.39 \mathrm{~g} / \mathrm{cm}^{3}$. Taking those molecules as distributed in water of a density of $1.0 \mathrm{~g} / \mathrm{cm}^{3}$, the authors obtained theoretical densities of 1.26 and $1.33 \mathrm{~g} / \mathrm{cm}^{3}$ (and $\mathrm{H}_{2} \mathrm{O}$ contents of 147 and 85 weight parts per 100 weight parts of nucleic acid) for the samples of nucleic acid and nucleoprotein, respectively. The authors (Josse et al., 1961) explained this discrepancy by assuming that nucleic acid filaments were not well-crystallized and, therefore, the amorphous areas were characterized by a lower degree of hydration in comparison with crystalline areas. However, they did not substantiate this assumption. In our opinion, the equilibrium $\mathrm{H}_{2} \mathrm{O}$ content is determined by the total content of hydrophilic groups, whereas the degree of crystallinity of the initial sample could influence only the rate of approach to the equilibrium in a humid medium.

After the work by Zimmerman \& Pheiffer (1979), an opinion existed that the number of base pairs per turn of the DNA helix is the same in solids and in solutions. However, this work 
does not contain data sufficient for such a conclusion. First, the polarized-light technique applied in the work is insufficient to exclude the occurrence of bunches of very small diameters ranging within several tens of nanometers and is inapplicable to concentrated solutions. Second, the contact of the DNA fiber with water is too short-term to postulate that the equilibrium wetting of the DNA molecules is achieved and no data confirming the DNA- $\mathrm{H}_{2} \mathrm{O}$ equilibrium (i.e., correlation with the DNA-to- $\mathrm{H}_{2} \mathrm{O}$ ratio in sperm) are presented. The experiment does not reveal the amount of water actually bound with the DNA molecules. Meanwhile, at the first step of wetting, waters quickly elevate into the phase of DNA as a result of the capillary effect and an $\mathrm{H}_{2} \mathrm{O}$ portion not bound with the DNA molecules might exist around them. Subsequent hydration proceeds slowly, since the process is limited by the rate of water diffusion in the thin capillary. Hydration of the phosphate groups of DNA proceeds apparently rather fast. This is caused by the fact that each positively polarized Patom is located in the center of a tetrahedron formed by negatively polarized O-atoms and movable water dipoles neutralize O-atoms with a significant gain in energy. This process disperses the fiber DNA helixes from each other over the capillary cross-section. However, the equilibrium hydration of the DNA helixes should also include hydration of the N-bases by liquid water. This process is extremely slow and the equilibrium is being established for several months (Ostrovskii et al., 2000, 2001). Slowness of hydration of the $-\mathrm{NH}_{2} \cdots \mathrm{O}=$ bonds is caused by the steric hindrances and smallness of the energy gain for this process (Ostrovskii et al., 2000, 2001). Therefore, we think that the equilibrium hydration could not be achieved in the experiments of Zimmerman \& Pheiffer (1979). This consideration shows that the conclusion of these authors on the equality of the number of the base pairs per one helix turn for solid and dissolved DNA has no ground.

It is commonly supposed that the B-DNA double helix characterizes the DNA state in living matter. However, its structural parameters obtained in different works differ noticeably. For example, values of $10.6 \pm 0.1$ (Rhodes \& Klug, 1980), $10.4 \pm 0.1$ (Wang, 1979), 10.1 (Drew et al., 1980), and 9.95 (Zimmerman \& Pheiffer, 1979) were obtained for the number of the purine and pyrimidine bases corresponding to the full turn of the double helix. Such a scatter in these values is too wide for works on specification of the structural parameters, and the nature of this scatter requires a special discussion.

The numerous experimental and calculated data considered above show that the DNA structure in the natural semi-liquid highly-concentrated aqueous systems depends on the $\mathrm{H}_{2} \mathrm{O}$ concentration, that the water content in the crystal DNA samples used for specification of the DNA structure is much less than the water content in sperm, and that, therefore, the actual DNA structure differs from the well-known W-C model.

A new understanding of the $\mathrm{H}_{2} \mathrm{O}$ effect in biological processes was proposed on the basis of the assumption on the principal role of water structuring and de-structuring around individual groups of biologically important substances in highly-concentrated semi-liquid $\mathrm{H}_{2} \mathrm{O}$-substrate systems (Ostrovskii \& Kadyshevich, 2000, 2002). We paid attention to the surprising agreement between the sizes of the individual functional groups of the DNA (and RNA) molecules and the free sizes of the gas-hydrate structural cavities.

Figures $4 \mathrm{~b}$ and $4 \mathrm{e}$ illustrate the size agreement between the large and small cavities of structure II and the N-bases and phosphate groups of DNA molecules, respectively. Each of these figures is given in scale. The sizes of ribose groups allow their housing within either small or large cavities. Final conclusion on the best agreement between the ribose size and the size of one of the kinds of these cavities should be made on the basis of the threedimensional PC modeling. 

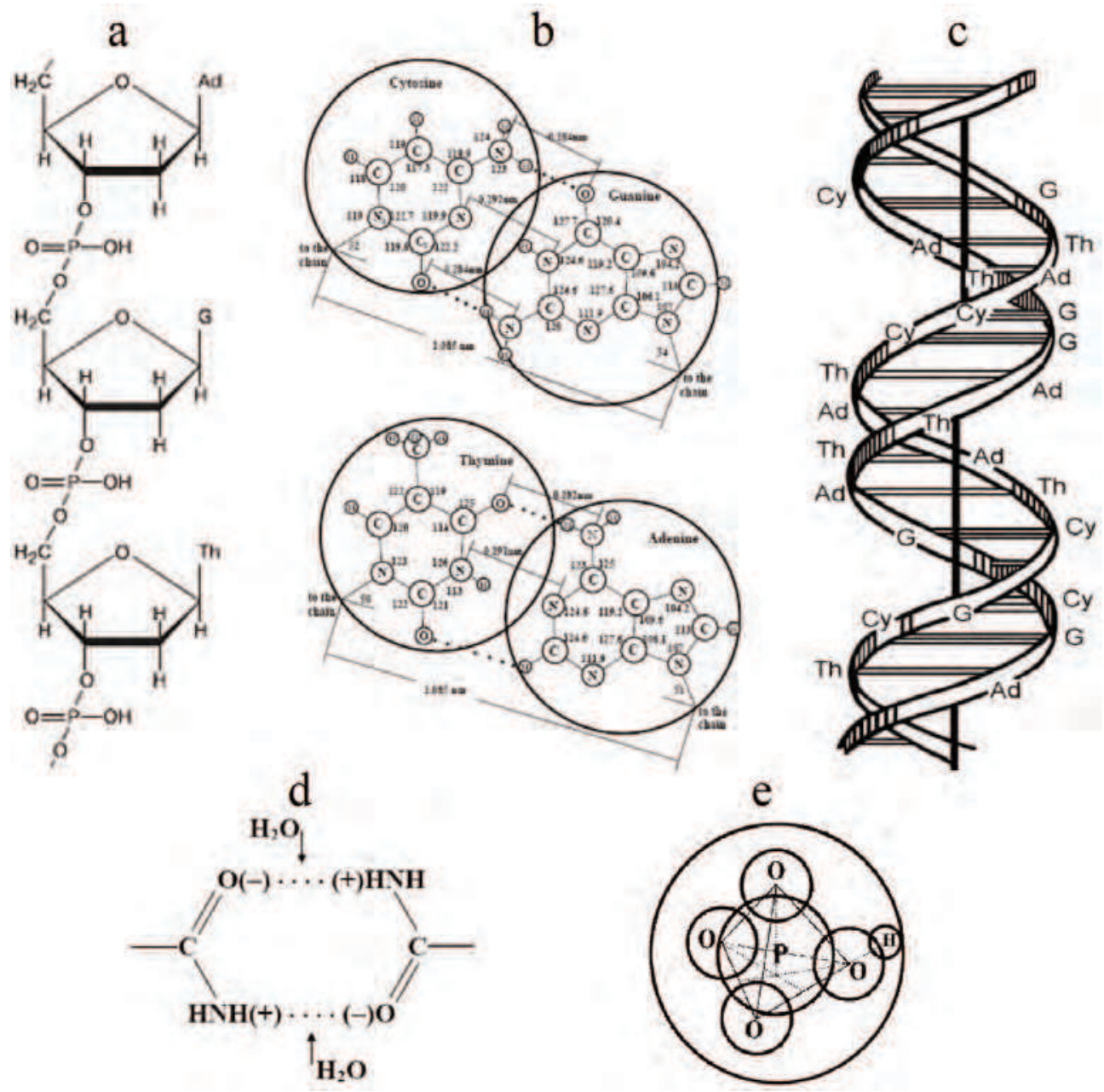

Fig. 4. (a) Fragment of a single DNA molecule; (b) scaled schematic representation of pairing between N-bases of two DNA molecules in the double helix structure; the valence angles are given in degrees, circles of diameter $0.69 \mathrm{~nm}$ correspond to the free diameter of the large cavity in the hydrate structure II; (c) schematic representation of a double-helix fragment formed by two DNA molecules; (d) scaleless scheme of AG-AG pairing of two adjacent PAA molecules; (e) scaled schematic representation of a phosphate group inside a small cavity of hydrate structure II (a circle of diameter $0.48 \mathrm{~nm}$ corresponds to the free diameter of the small cavity).

In Ostrovskii \& Kadyshevich (2000, 2002), the following concept for the semi-liquid highlyconcentrated structure of DNA- $\mathrm{H}_{2} \mathrm{O}$ systems was developed. Each helix segment containing two pairs of N-bases can be housed in a volume of $5.268 \mathrm{~nm}^{3}$ including 8 large and 16 small cavities of hydrate structure II formed by 136 water molecules. At the DNA-water equilibrium in vivo, hydrate structure II, whose large cavities are filled with fragments of 
DNA, is formed. This structure corresponds to a complete neutralization of the affinity of DNA molecules with respect to each other. Therefore, when water penetrates into the equilibrium system from the outside, the double helix gradually unwinds and the DNA molecules begin to push off each other.

We calculate the DNA structure and the DNA- $\mathrm{H}_{2} \mathrm{O}$ system density to have a possibility for their comparison with the available data. To compute the structural characteristics of the equilibrium state, we consider the transformation of the B-form of DNA (Wilkins, 1961), which we regard as nonequilibrium. The full diameter of the double helix of DNA (2.58 nm) is obtained by adding the distance between the axes of $\mathrm{P}$ atoms of two complementary DNA molecules $(2.00 \mathrm{~nm}$, (Wilkins, 1961)), the doubled $\mathrm{O}=\mathrm{P}$ bond length $(0.308 \mathrm{~nm})$, and the doubled V-d-W oxygen radius $(0.272 \mathrm{~nm})$. Then, with a knowledge of the helix step $(3.4 \mathrm{~nm}$, (Wilkins, 1961)), we compute the helix length (the planar evolvent of the helix) per nitrogen base $(0.879 \mathrm{~nm})$. The following computations are performed by the method of successive iterations under the assumption that wetting of the B-form up to equilibrium does not change the helix diameter, but only increases the helix step. Varying the helix step, we compute the volume of the double helix, the number of pairs of nitrogen bases, and the number of large cavities in hydrate structure II per helix convolution. Then, we perform the iteration procedure up to a helix step corresponding to the $1 / 4$ ratio between the number of large cavities and the number of pairs of N-bases. This computation is the critical point in our analysis. The resultant number of pairs of nitrogen bases per helix convolution is equal to 11.25. This value corresponds to a helix step of $5.67 \mathrm{~nm}$ and to 5.627 unit cubic cells of hydrate structure II per helix convolution. Our computation of the density of the equilibrium DNA- $\mathrm{H}_{2} \mathrm{O}$ system gives a value of $1.161 \mathrm{~g} / \mathrm{cm}^{3}$. This result is significantly lower than a density of $1.34-1.39 \mathrm{~g} / \mathrm{cm}^{3}$ measured by Feughelman et al. (1955) for DNA wetted under nonequilibrium conditions. The application of the above-described notions of the DNA structure to the samples (Wilkins, 1961) characterized by 10 pairs of nitrogen bases per helix convolution, a helix step of $3.4 \mathrm{~nm}$, and an above-specified diameter of $2.58 \mathrm{~nm}$, gives a density value of $1.351 \mathrm{~g} / \mathrm{cm}^{3}$. Unlike the density reported by Wilkins (1961) (1.28 $\left.\mathrm{g} / \mathrm{cm}^{3}\right)$, which is based on the model proposed by Crick \& Watson (1954), the value 1.351 $\mathrm{g} / \mathrm{cm}^{3}$, which we obtained based on our model, correlates well with the density of 1.34-1.39 $\mathrm{g} / \mathrm{cm}^{3}$ of the samples used by others (Watson \& Crick, 1953; Crick \& Watson, 1954; Feughelman et al, 1955) to formulate ideas about DNA structure. The density is calculated as the sum of the water and DNA contributions. Apparently, this calculation shows that the notion on the DNA- $\mathrm{H}_{2} \mathrm{O}$ highly-concentrated media as on structured semi-liquid systems is justified, at least, no less than any other idea aimed at understanding such complicated and simple natural phenomenon as life. It is important that the notion on an equilibrium $\mathrm{H}_{2} \mathrm{O}$ content in DNA- $\mathrm{H}_{2} \mathrm{O}$ systems is a conventional one. The case is that it can be achieved only in the isolated DNA- $\mathrm{H}_{2} \mathrm{O}$ systems under $100 \%$ humidity. Actually, when nutrients diffuse into a system, no equilibrium can be reached because the DNA molecules are at different steps of mitosis and the major portion of them are not completely watered.

Thus, at this step of our review, at least four statements weigh heavily the importance and, possibly, fundamental significance of the phenomenon of hydrate formation in the totality of the natural processes, which has the collective name "life".

1. No living matter exists in waterless media, and some other elements are necessary for its origination and existence; therewith, waters always tend to form hydrate structures within a narrow range of natural conditions when waters and other molecules are 
already movable sufficiently to diffuse taking the thermodynamically-preferable positions and when other molecules, which are more chemically active, are already capable to react chemically with each other but have still so small reactive ability that they pass step-by-step all thermodynamically-possible steps of their chemical interaction until the heat of these reactions, diffusion of excessive water from outside, or any external phenomena or processes destroys the hydrate structures.

2. The sizes of individual functional groups of DNA (and RNA) coincide almost entirely with the free sizes of the cavities of hydrate structure II (until the special threedimensional PC analysis is finished, we do not exclude that the hydrate structure $\mathrm{H}$ is also appropriate).

3. The results of sorption-desorption and calorimetric experiments weigh heavily the hydrate structure formation in the PAA- $\mathrm{H}_{2} \mathrm{O}$ system at about $290 \mathrm{~K}$.

4. The assumptions on the existence of the hydrate structure in the sperm-water system and on an unwinding (and "stretching" along the surface of the cylinder of constant diameter) of the DNA double helixes with wetting lead to realistic values of the DNA$\mathrm{H}_{2} \mathrm{O}$-system density.

We will see somewhat later that, in fact, a number of other statements also count in favor of the significance of the hydrate-formation phenomenon for the processes that are under consideration in this review.

\section{Life origination hydrate hypothesis (LOH-hypothesis)}

\subsection{Principal content of the LOH-hypothesis}

According to the LOH-hypothesis, the LMSEs and proto-cells originated and, possibly, originate in our days from $\mathrm{CH}_{4}$ (or other $\mathrm{CH}_{4}$-hydrocarbons), niter, and phosphate under the Earth's surface or seabed within honeycomb structures of hydrocarbon hydrates. It is well known that $\mathrm{CH}_{4}$ (and also aliphatic, alicyclic, and aliaromatic compounds) is capable of interacting with nitrate ions under pressure, yielding different organic substances (M. Konovalov's reaction, 1888 (Konovalov, 1893)). The underground deposits of $\mathrm{CH}_{4}$ and other hydrocarbons could result from the reaction between $\mathrm{H}_{2}$ and $\mathrm{CO}_{2} ; \mathrm{CO}_{2}$ could be produced from carbonates as a result of their thermal decomposition induced by the gravitational compression of the young-Earth crust (Ostrovskii, 2010). Hydrogen could be desorbed from the solid aggregates of which the young Earth was composed; these aggregates had adsorbed $\mathrm{H}_{2}$ from nebula before they were captured by the Earth's gravitational force in the period of the Earth origination as a planet body (Ostrovskii \& Kadyshevich, 2007, 2008). Thus, the living-matter sources are $\mathrm{H}_{2}$, carbonates, nitrates, and phosphates, which resulted from transformation of the nebula. The nebula that was the progenitrix for the Solar System arose after the supernova explosion (Kadyshevich \& Ostrovskii, 2010b).

The LOH-hypothesis allows for answering the following questions (Kadyshevich \& Ostrovskii, 2009, 2010c, 2010d; Ostrovskii \& Kadyshevich, 2010, 2011). (1) In what phase did the LMSEs form? (2) From what substances did the LMSEs form? (3) By what mechanism did the N-bases, riboses, and nucleosides form? (4) Is Nature capable of synthesizing LMSEs from minerals with no external energy? (5) How had methane hydrate originated? (6) How did $\mathrm{CH}_{4}$ and $\mathrm{NO}_{3}{ }^{-}$meet? (7) Why no substance but $\mathrm{NO}_{3}{ }^{-}$reacted with $\mathrm{CH}_{4}$-hydrate? (8) How did DNA- and RNA-like molecules form from nucleosides? (9) Is there a relation between DNA and RNA formation, on the one hand, and the atmosphere composition, on the other hand? (10) Why do only five chemical elements usually enter the DNA and RNA 
composition? (11) Why are N-bases entering DNA and RNA similar in their composition and structure? (12) Why are N-bases and riboses limited in size? (13) Why are N-bases not identical? (14) Why do only five N-bases usually enter the DNA and RNA composition and why do other $\mathrm{N}$-bases, such as $\mathrm{X}$ (xanthine), sometimes enter the DNA and RNA compositions? (15) Could DR, DDR, Th, and U exist simultaneously in a reaction mixture containing $\mathrm{CH}_{4}$ and niter? (16) How had it happened that the sequences of N-bases in DNA and RNA molecules are not random? (17) Why did Nature choose DR and DDR, but not their L-enantiomers or mixtures of enantiomers for DNA and RNA syntheses? (18) How did proto-cells originate?

\subsection{Several answers to the questions on living matter origination}

Each of the above-listed questions is answered with comments in Ostrovskii \& Kadyshevich (2007) and Kadyshevich \& Ostrovskii (2009). Short answers on some of the questions are given in the first paragraph of Section 3.1. Several questions will be considered below.

First, let us dwell on question (4). The reaction of formation of the full set of N-bases and DR necessary for origination of an RNA molecule can be written in the form

$$
a_{1} \mathrm{KNO}_{3}+a_{2} \mathrm{C}_{\mathrm{n}} \mathrm{H}_{\mathrm{m}}=a_{3} \mathrm{U}+a_{4} \mathrm{Ad}+a_{5} \mathrm{Cy}+a_{6} \mathrm{G}+4 \mathrm{DR}+a_{1} \mathrm{KOH}+a_{7} \mathrm{H}_{2} \mathrm{O}+a_{8} \mathrm{~N}_{2},
$$

where $\mathrm{C}_{\mathrm{n}} \mathrm{H}_{\mathrm{m}}$ is the formula of a source aliphatic hydrocarbon and $a_{1} \div a_{8}$ are the stoichiometric coefficients (therewith, the stoichiometric coefficients for $\mathrm{KNO}_{3}$ and $\mathrm{KOH}$ are the same). (We showed by a thermodynamic consideration that, in the equilibrium system, the occurrence of $U$ and DR means the occurrence of Th and DDR in the system (Kadyshevich \& Ostrovskii, 2009)). Equation (1) shows how many molecules of each of the source substances are consumed and how many molecules of each of the products are produced counting on $4 \mathrm{DR}$ molecules in the average over the chain. This equation corresponds to the situation when oxygen of niter reacts completely; i.e., $\mathrm{O}_{2}$ is not produced. The calculations performed for the sets characterized by different $r$ values $\left(r=\left(a_{3}+a_{4}\right) /\left(a_{5}\right.\right.$ $\left.+a_{6}\right)$ ) allow the following conclusions. The changes in the Gibbs free energy for the reactions of niter with $\mathrm{CH}_{4}, \mathrm{C}_{2} \mathrm{H}_{6}, \mathrm{C}_{3} \mathrm{H}_{8}, \mathrm{C}_{2} \mathrm{H}_{4}$, and $\mathrm{C}_{3} \mathrm{H}_{6}$ are negative and rather great in magnitude and vary only slightly with the $r$ value. For example, the $\Delta_{\mathrm{i}} G^{0}$ values for the reaction between niter and methane at $r=0.0625,1.00$, and 16.0 are equal to $(\mathrm{kJ} / \mathrm{mol})-8227,-8281$, and -8336 , respectively, and the $\Delta_{\mathrm{i}} G^{0}$ values for the reaction between niter and ethane at $r=$ $0.0625,1.00$, and 16.0 are equal to $-6050,-6104$, and -6159 , respectively. These results mean that the LMSEs could originate from methane hydrocarbons and niter at the expense of the internal energy of the source substances and that thermodynamics allows wide variations in relative yields of $\mathrm{N}$-bases. Different sets of $\mathrm{N}$-bases could originate in different historical periods in any one region or in any one historical period in different regions of the globe. Our estimations are performed for the standard conditions. However, the $\Delta_{\mathrm{i}} \mathrm{G}^{0}$ values for the reactions under consideration are so high in magnitude that there are no doubts that these reactions are feasible within the phases of hydrocarbon hydrates under real conditions.

$\mathrm{CH}_{4}$ was captured by the Earth in the period of planet formation or was produced in intraterrestrial reservoirs filled with the heated $\left(\mathrm{H}_{2}+\mathrm{CO}_{2}\right)$ mixtures by the following reaction (Ostrovskii \& Kadyshevich, 2007; Kadyshevich \& Ostrovskii, 2009):

$$
4 \mathrm{H}_{2}(\mathrm{~g})+\mathrm{CO}_{2}(\mathrm{~g})=\mathrm{CH}_{4}(\mathrm{~g})+2 \mathrm{H}_{2} \mathrm{O}(\mathrm{lq})
$$


The change in the standard Gibbs energy for this reaction is rather high in magnitude and is equal to $-130.6 \mathrm{~kJ} / \mathrm{mol}$; i.e., the reaction should proceed up to almost complete consumption of one of the source gases under rather wide variations in the reaction parameters. With time, the exothermal process of Earth's crust compacting was decaying and the Earth's crust was cooling. This phenomenon favored formation of $\mathrm{CH}_{4}$-hydrate (and hydrates of other hydrocarbons) within underground reservoirs. Near some of the $\mathrm{CH}_{4}$-hydrate deposits, niter deposits are located, for example, along the west coast of Central and South America. Apparently, the niter deposits were still more abundant in the Arhean period, because niter is $\mathrm{H}_{2} \mathrm{O}$-soluble. In the regions characterized by neighboring locations of $\mathrm{CH}_{4}$-hydrate and niters, $\mathrm{NO}_{3}{ }^{-}$-ions diffused into the $\mathrm{CH}_{4}$-hydrate structures and reacted with methane.

$\mathrm{CH}_{4}$ is a rather inert substance, and, under conditions of $\mathrm{CH}_{4}$-hydrate stability, very few minerals are capable of interacting chemically with it. The $\mathrm{CH}_{4}$-hydrate structure as if "swallows" selectively the $\mathrm{NO}_{3}{ }^{-}$-ions and converts them to N-bases and riboses. Diffusion of $\mathrm{NO}_{3}{ }^{-}$-ions into the structure is stimulated by the decrease in the Gibbs free energy in the process of chemical interaction of $\mathrm{NO}_{3}{ }^{-}$with $\mathrm{CH}_{4}$. A similar situation arises when phosphate ions enter in contact with the hydrate structure filled with nucleosides. The foreign atoms rarely entering the DNA and RNA compositions in addition to $\mathrm{C}, \mathrm{N}, \mathrm{P}, \mathrm{O}$, and $\mathrm{H}$ come from the walls of the reservoirs filled with $\mathrm{CH}_{4}$-hydrate, from admixtures to source $\mathrm{CH}_{4}$ and $\mathrm{H}_{2} \mathrm{O}$, etc.

The sizes of each of the LMSEs were limited by the sizes of the cavities. The close agreement between the sizes of individual groups of DNAs and RNAs, on the one hand, and the free sizes of the cavities, on the other hand, testifies for this assumption (Fig. 4b, e). The large cavities are as if "moulds" for N-bases, and the small cavities are as if "moulds" for phosphate groups. As was mentioned above, riboses can be housed in small or large cavities. (The large cavities of structure $\mathrm{H}$ are somewhat "more roomy" than those of structure II, and we cannot exclude that structure $\mathrm{H}$ is the matrix for LMSE formation). Just the sizes of the structural cavities limit growing of the functional groups. They are similar because their formation proceeds from the same substances, in the cavities of the same size, slowly, step-by-step, decreasing the Gibbs energy over the entire $\mathrm{CH}_{4}$-hydrate localization up to full filling of the cavities. The entire localization reaches its final state by the same time. N-bases are similar but not identical, and the cause of their nonidentity is as follows. Let one of the cavities be completely filled with a purine base in such a way that the atomic $\mathrm{V}-\mathrm{d}-\mathrm{W}$ radii of this N-base overstep the boundary of this cavity. In this case, the neighboring cavity should contain an N-base of a smaller size, because the distance between any two atoms of adjacent molecules should exceed the sum of their $\mathrm{V}-\mathrm{d}-\mathrm{W}$ radii.

Apparently, just the thermodynamics is instrumental in selection of N-bases to be further incorporated in the composition of nucleic acids. This opinion can be illustrated by the reaction between $\mathrm{G}$ and $\mathrm{H}_{2} \mathrm{O}$ with formation of xanthine $(X)$ and $\mathrm{NH}_{3}$. For this reaction, $\Delta\left(\mathrm{G}^{0}\right)=+7.32 \mathrm{~kJ} / \mathrm{mol}$. This value shows that, in a system, where reactions proceed in the vicinity of $273 \mathrm{~K}$ and so slowly that the equilibrium relations between reacting components keep constant in time, $\mathrm{G}$ should usually prevail over $\mathrm{X}$ but, under some conditions, the relative amounts of the last may be noticeable. We think that this is the cause of the usual significant prevailing of G over X in the DNA molecules (Kadyshevich \& Ostrovskii, 2009). As for the DNA and RNA monochirality, we assume that it is a natural inevitable consequence of the $\mathrm{CH}_{4}$-hydrate matrix geometry. Apparently, only D-riboses are capable to "touch" both, an N-base and a phosphate group; this structural feature leads to the 
consumption of the D-forms and to the shift of the equilibrium to formation of just Dmolecules. This assumption should be verified by three-dimensional computer simulation.

The LMSEs formed within the structural cavities reacted with each other with formation of nucleosides. After diffusion of phosphates into the structure, the DNA- and RNA-like molecules formed. Then, as water, niter, and phosphates diffused into the system, the structure liquidized and transformed into a structured soup in which the simplest living organisms began the long history of their development and expansion over the world.

By analogy with the cellular cytoplasm, we term this soup super-cytoplasm. In the supercytoplasm, all the substances necessary for the existence and development of the primary DNA- and RNA-like substances could be synthesized on the basis of $\mathrm{CH}_{4}$ and of phosphates and niters that diffused from the environment. We have already cited articles in which nucleic acids were shown to self-replicate (Orgel, 1992, 2000; Cech \& Bass, 1986; Li \& Nicolaou, 1994). Under appropriate conditions, this led to an increase in the concentrations of nucleic acids and organophosphorous substances within the super-cytoplasm. Increasing in the concentrations to a certain critical level led to precipitation of phosphor-containing membranes around DNAs and to origination of proto-cells. Thus, in addition to the supercytoplasm, intracellular cytoplasm appeared. After that, nucleic acids began to develop and replicate inside the cells and the cells began to divide similarly to the cells of the present prokaryotes. This assumed mechanism is described in more detail elsewhere (Ostrovskii \& Kadyshevich, 2007).

Figure 5 gives the principal scheme for living-matter origination by the LOH-hypothesis.

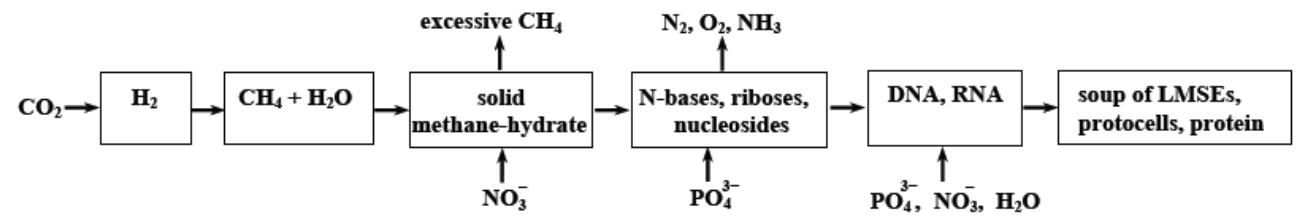

Fig 5. General hypothetical scheme of living-matter origination.

According to the LOH-hypothesis, living matter originated repeatedly. In any one localization, a multitude of different DNA- and RNA-like molecules and proto-cells could originate in the same time period, and, in different localizations, multitudes of progenitors of different species could originate in different time periods. The lengths and degrees of perfection of the DNA-like chains that originated within a hydrate structure were directly dependent on the period of their growth within an underground "incubator". Therefore, the first ancient prokaryotes appeared earlier than the eukaryotes with longer and more complicated DNA chains. New populations of both prokaryotes and eukaryotes appeared repeatedly in the Earth's history. Thus, the conclusion of Buss (1987) on the repeated originations of new species obtains a natural explanation. The LOH-hypothesis is capable of explaining the occurrence of numerous prokaryotic and eukaryotic species without Darwin's theory of evolution resulted from interspecific variations and natural selection as the leading causes of the species diversity of the prokaryotic and eukaryotic living matter. It cannot be excluded that living matter originates in our time.

In Ostrovskii \& Kadyshevich (2007) and Kadyshevich \& Ostrovskii (2009), it was shown that a number of natural phenomena (e.g., Schippers et al., 2005; MacDonald et al., 1996; 
Davidson et al., 1986 ; Tresher et al.,1992; Oborin \& Khmurchik, 2008) count in favor of this hypothesis. Menor-Salván et al. (2009) found that the repeated freezing-unfreezing cycles stimulate formation of some $\mathrm{N}$-bases in urea solutions under the methane atmosphere. Apparently, this effect can be explained by hydrate-structure formation under freezing.

\section{DNA replication, mitosis, and binary fission hypothesis (MRH-hypothesis)}

\subsection{The water state in living systems and the common physicochemical concept of DNA replication}

An analysis performed by us (Ostrovskii \& Kadyshevich, 2000, 2002) on the basis of available works and the data presented above led us to the following views on the water state in living systems. The processes of water structuring and de-structuring in living cells play a decisive role in the interactions of living cells with their environment. In definite periods of the cell cycle, water structuring within cells binds water diffusing into them and thus prevents excessive swelling and rupture of the cell. Namely, the intensity of water structuring is maximal when cells are "mature" and large and the danger for their rupturing is critical, while it is low when the cells are "young" and small and water diffusion from outside is not dangerous for their existence. The rate of cell swelling depends on the cell size, thickness and hydrostatic resistance of the semi-permeable membrane (plasma membrane with or without cell wall), composition of the cell interior, transport of environmental substances and metabolites, and degree of hydrate formation (of water structuring). The values of the osmotic pressure and of the Donnan effect are the external attendant integral manifestations of the exchange by waters, mineral and organic substances, and ions between living cells and their environment; the significance of artificial regulations of metabolism through variations of these effects is of common knowledge. The intracellular $\mathrm{H}_{2} \mathrm{O}$ content varies depending on the phase of the cell cycle, and, at every instant, different cells are in different phases of the cell cycle. For ribose, phosphate groups, unpaired N-bases, and paired N-bases belonging to DNA, the in-vivo integral molar strength of water binding, excessive in comparison with the energy of $\mathrm{H}_{2} \mathrm{O}$ condensation at the liquid pure-water surface, is different and depends on the degree of wetting of the corresponding functional groups of DNA. The $\mathrm{H}_{2} \mathrm{O}$ content in a living cell at each phase of the cell cycle is strictly defined. Diffusion of excessive water into a cell leads to neutralization of the DNADNA interactions and moving apart of the paired DNA molecules. In water-deficient media, the DNA-DNA binding in double helixes is realized predominantly through AGs of Nbases. Decreasing in the environmental water concentration below some critical value leads to depression of the intracellular activity and to gradual degradation of the cells.

One of the phenomena that have stimulated the hypotheses considered in this section is the following one. As was mentioned above, the sizes of each of the N-bases entering the DNA and RNA molecules are equal to the free sizes of the large cavities of hydrate structure II (Fig. $4 \mathrm{~b}$, e). Thus, the sizes of the gas-hydrate structure II agree well with the sizes of all functional groups of DNA and RNA molecules. It is seldom that such agreements in Nature are causeless. Looks like Nature has a tea-set with "baking cups" ranged for each of the DNA and RNA functional groups.

The common physicochemical concept of replication is as follows. When waters and necessary nutrients enter continuously the system, each DNA double helix swells up to a critical (conventionally: equilibrium) state when the hydrate envelopes around the N-bases 
are formed completely. Under such conditions, DNA-DNA interactions are neutralized, the DNA double helix reaches its critical length, and the DNA mono-strands begin to move aside from each other, starting from their ends. The nutrients diffuse into the fresh vacancies and build a new complementary DNA molecule on each of the "orphaned" DNA monostrands. Therewith, the newly formed N-bases displace waters because, at small degree of watering, the AG-AG bond is stronger than the AG- $\mathrm{H}_{2} \mathrm{O}$ bond. After formation of two new DNA mono-strands, each paired with the corresponding maternal mono-strand, i.e., upon formation of two daughter double helixes, new waters diffuse to the AG-AG bonds. These waters weaken and destroy the AG-AG bonds, because excessively-watered hydrate structures are unstable. The newly-formed DNA double helixes move aside from each other. After that, the process repeats itself, but it includes now two daughter double helixes instead of the maternal one.

\subsection{The processes of DNA replication and of formation of new cells in more detail}

The present generally-accepted notion on the DNA-replication and mitosis mechanisms is formulated, to a great extent, on the basis of the light micrographs corresponding to different phases of the cell cycle (see, e.g., Oparin, 1927; Alberts, 2002). The NMR method gives no possibility to determine the sizes of different minor details, the special benefits of the confocal laser scanning microscopes against the non-laser optical microscopes are not principal for size measurements, and methods requiring treatment of samples by vacuum, hard radiation, or freezing give no possibility for controlling the temporal variations in sizes of cell components in living matter. As for the light micrographs, they, on frequent occasions, cannot be explained unambiguously. The point is that the maximum degree of magnification of light microscopes is limited by light diffraction, and the resolution of the best classic optical microscopes is no more than $200 \mathrm{~nm}$. This means that an object of $200 \mathrm{~nm}$ in diameter is seen under microscopes as a point, which can be detailed by no photographic or PC means. Meanwhile, the $\mathrm{C}-\mathrm{C}$ bond is about $0.15 \mathrm{~nm}$; i.e., the carbon chain consisting of 1300 atoms or a graphite plane consisting of about 1.7.106 atoms is seen as a point, and the attempts to use PC software for revealing the interior structures of such points are questionable. Moreover, the light microscopes give almost no information on the intracellular transformations proceeding in the interphase covering about $90 \%$ of the cellcycle period. Thus, the micrographs give limited information for estimating the comparative variations in the form and density of chromosomes in the course of the observable portion of cell cycles; however, they give no grounds for description of chromosome details smaller than 1300 atoms in length or 1.7.106 atoms in plane. Meanwhile, the examples of excessive insubstantial detailing of the chromosome-transformation phases are available in literature and can lead to erroneous views on the degree of clarification of the real mechanisms of intracellular processes if these views are presented as results of analyses of micrographs rather than as authors' suppositions.

Below, we propose a hypothetical physicochemical explanation for some processes proceeding in the course of mitosis and DNA replication. Our MRH-hypothesis relates to the maternal function of cells rather than to their function as a chemical factory producing organic materials. In this connection, we do not consider the outside-cell transport of organic substances and minerals and the chemical content of the intracellular reactions. We believe that a number of phenomena observable during mitosis and interphase can be explained on the basis of well-known physicochemical regularities inherent in the processes 
of continuous water diffusion into cells, formation and destruction of hydrate structures around N-bases belonging to the DNA molecules, and variations in the water concentration and precipitation and dissolution of organic substances in the cytoplasm.

In order for any chemical process to proceed in a fluid medium and to produce a desired product, the following conditions should be fulfilled: (1) the thermodynamics should allow proceeding of this process; (2) the concentrations of the reactants should be rather high; (3) the steric hindrances should not be insuperable; (4) the temperature should be rather high in order for the molecular mobility to be provided; (5) the rate of formation of the desired product should be higher than the rate of its subsequent transformations if the last are possible; and (6) no one of the source reactants should be consumed in any side reaction before its action in the desired reaction.

As was mentioned above, DNA replication is the central phenomenon inherent in living matter. Generally speaking, cells can duplicate or not duplicate, but duplication of chromosomes is necessary for the existence of living matter and transmission of the hereditary features. Apparently, DNA replication could proceed under some conditions without mitosis. (Similar ideas were expressed earlier (Orgel, 2000; Zielinski \& Orgel, 1987)). Therefore, we will consider the cycles of replication and of cell division separately. Let the replication cycle proceed from the moment of separation of sister chromatids in a mother cell and formation there of two daughter chromosomes of the first generation to the moment of separation of sister chromatids in a daughter cell and formation there of two daughter chromosomes of the second generation, and let the cell-division cycle proceed from the moment of division of the mother cell to the moment of division of the daughter cell. Thus, in our consideration, the replication cycle does not coincide with the cell-division cycle.

Water is necessary for the processes of mitosis (in the case of prokaryotes, of binary fission) and DNA replication. It diffuses (in parallel with organic and inorganic substances) into living cells continuously from the outside through the cell membrane, and, as noted above, the rate of water diffusion is time-dependent. The water structuring within cells stimulates continuous water flow into cells.

Bearing in mind six conditions formulated above in this section and the involved data presented in the previous sections, we give the hypothetical explanation for the binary fission and DNA replication processes inherent in prokaryotes and in eukaryotes and consider their common features and peculiarities.

First we apply the MRH hypothesis to prokaryotes. Prokaryotes are the simplest cellular organisms, and analyses of their cell cycle can reveal the fundamental necessary and sufficient features of metabolism purified as much as possible of side processes and phenomena that are not necessary for metabolic processes. Meanwhile, the necessary and sufficient factors of metabolism of eukaryotes may be obscured by the occurrence of some intracellular organelles, the absence of which does not exclude the principal possibility of metabolism. It is known that each of the prokaryotic cells usually has one DNA double helix termed chromosome and consisting of two circular DNA mono-strands bound together through purine-pyrimidine H-bonds. The prokaryotic cell cycle includes replication of this chromosome and binary fission of the cell.

Consider the hypothetical mechanisms of the prokaryotic replication cycle. Before separation of sister chromatids into two daughter chromosomes, $\mathrm{H}_{2} \mathrm{O}$-dipole layers are formed along each of two coupled circular DNA double helixes. These double helixes repulse each other by an electrostatic force, the nature of which will be explained below, and 
two daughter chromosomes (of the first generation) move apart to the opposite sides of the cell and take up positions in immediate proximity to the plasma membrane. Just this moment is taken by us as the onset of the replication cycle. For the intra-cellular processes to go in the strict sequence, in accordance with the stepwise decrease in the free energy over the entire volume of the intra-cellular cytoplasm, waters should penetrate slowly into each double helix, envelope the N-bases, and house them into cavities similar to those existing in gas-hydrate structure II. Just such a process is in progress after formation of the daughter chromosomes. It starts about synchronously at several different locations of the chromosome, because different locations have no preferences for water structuring (this statement will be confirmed below). The first step of this process is thermodynamically caused and is analogous to the process of $\mathrm{H}_{2} \mathrm{O}$ sorption by PAA (Fig. 2e) under conditions when the $n$ value is somewhat higher than unity but is significantly lower than 17; the energy gain for this process is equal to the difference between the binding energy of two neighboring N-bases belonging to different DNA mono-strands and the algebraic sum of the binding energies of waters with two N-bases and the energy of electrostatic repulsion of two newly-formed water envelopes housing the N-bases. A similar process at $100 \%$ humidity goes spontaneously (Fig. 2b); i.e., it is characterized by a negative change in the Gibbs free energy. These experimental results give grounds to assert that the process of hydration of the AG-AG bonds is associated with a very small decrease in the Gibbs free energy and proceeds slowly and that formation of a water continuum and moving of AGs from each other should be thermodynamically caused when the water surrounding of neighboring $\mathrm{N}$ bases is sufficiently extended. Figure 2e shows that the difference between the molar heat effects of $\mathrm{H}_{2} \mathrm{O}$ sorption and $\mathrm{H}_{2} \mathrm{O}$ condensation at the liquid pure-water surface is rather small in magnitude and can be positive or negative depending on the degree of wetting of the substrate, i.e., that $\mathrm{H}_{2} \mathrm{O}$ sorption proceeds as a result of the entropy peculiarities. Each of the daughter chromosomes sorbs water intensively and the $\mathrm{H}_{2} \mathrm{O}$ inflow to the cell from the outside becomes inadequate for covering their water demands. Therefore, the chromosomes sorb $\mathrm{H}_{2} \mathrm{O}$ stored in the intracellular cytoplasm. Within the cell, two opposite $\mathrm{H}_{2} \mathrm{O}$ flows directed from the central region of the cell to the daughter chromosomes arise. Because the $\mathrm{H}_{2} \mathrm{O}$ density exceeds the densities of organic liquids, the $\mathrm{H}_{2} \mathrm{O}$ outflows from the central region of the cell lead to a decrease in the fullness of this cell region and to a decrease in the density of the intracellular medium in it. In addition, $\mathrm{H}_{2} \mathrm{O}$ depletion of the central cell region results in its supersaturation by phospholipids and other polymers. These phenomena initiate formation of a cleavage furrow and precipitation of excessive lipids in the equatorial plane of the cell and result finally in cell division in two daughter cells, each containing one daughter chromosome of the first generation. Thus, the binary fission realizes. Below, we consider one of the daughter cells.

The young daughter cell is small and water-deficient. However, the "water requirement" of the daughter chromosome is already satisfied partially and, therefore, the rate of water structuring around $\mathrm{N}$-bases of this chromosome is decreased. As a result, the water inflow through the plasma membrane leads to swelling of the cell. Meanwhile, the water inflow enriches the peripheral cytoplasmic layer by water, thus increasing its density, and weakens the chromosome-to-membrane cohesion. As a result, the chromosome moves into the cell central region, which is enriched (as compared to the peripheral region) with organic substances and, therefore, has a decreased density. The so-called nucleoid forms. By this, the process of water structuring around N-bases of the chromosome DNA double-strand is yet not completed; however, in some chromosome locations, the DNA-DNA interactions are 
already neutralized by waters and the rate of water uptaking by the chromosome is minimized. Such a situation initiates a new step of the DNA replication.

In this period, the process of construction of DNA-replicas on the basis of each mono-strand of the daughter chromosome starts. This process is stimulated by the appearance of chromosome regions where several neighboring DNA-DNA H-bonds are neutralized, i.e., by the appearance of minor primitive water-filled capillaries, and by the organic and mineral substances taken up by the cell together with the water inflow. Apparently, the process of DNA replication starts almost simultaneously at different DNA locations where the DNA-DNA H-bonds are neutralized, because the circular-chromosome locations do not differ but in the degree of hydration of the N-bases responsible for the H-binding of two DNA mono-strands. The data (Sclafani \& Holzen, 2007; Kornberg \& Baker, 2005; Alberts et al., 2002) showing that eukaryotic chromosomes begin to replicate in different chromosome locations simultaneously count in favor of the analogous phenomenon of multiplicity of start locations of DNA watering and subsequent replication in prokaryotes. To understand the mechanism of the replication process, the well-known peculiarities of water behavior in contact with microcapillaries or microslots (the so-called capillary condensation) and the above-given information about smallness of the difference between the energies of AG-AG, AG- $\mathrm{H}_{2} \mathrm{O}$, and $\mathrm{H}_{2} \mathrm{O}-\mathrm{H}_{2} \mathrm{O}$ interactions should be taken into consideration. It is well known that capillary condensation in solid-vapor systems starts at a relative humidity below $100 \%$ depending on the capillary diameter (more exactly, on the water-meniscus curvature). For the capillaries of a definite diameter, the start of capillary condensation is determined by the water concentration or, to be precise, by the water activity. In microcapillaries, when the capillary diameter and molecular interatomic distances are of the same order of magnitude, water capillary condensation can proceed in solutions with water activity significantly lower than unity. The process similar to the capillary condensation should proceed in living cells after the step of formation of $\mathrm{H}_{2} \mathrm{O}$ envelopes around $\mathrm{N}$-bases, because this step leads to some separation of the DNA mono-strands from each other and to some unwinding of the DNA double helixes. The process of capillary condensation of $\mathrm{H}_{2} \mathrm{O}$ promotes formation of small water continuums in the volume between $\mathrm{N}$-bases of the neighboring DNA monostrands. Formation of these $\mathrm{H}_{2} \mathrm{O}$ continuums leads to reorientation of water dipoles forming envelopes around N-bases, to partial neutralization of their dipole moment by the $\mathrm{H}_{2} \mathrm{O}$ continuums, and, as a result, to weakening of the binding between the water envelopes and $\mathrm{N}$-bases. Under such conditions, the $\mathrm{H}$-interactions between the $\mathrm{N}$-bases belonging to the DNA mono-strands and the nucleotides dissolved in the cytoplasm becomes more favorable thermodynamically than the H-binding between these N-bases and their water envelopes. Therefore, the nucleotides "moor" to these DNA mono-strands and form H-bonds with them, initiating formation of two sister chromatids of the second generation (as was said above, we do not consider the chemical content and, therefore, do not consider the details of this chemical process). So long as the $\mathrm{N}$-bases are not enveloped by $\mathrm{H}_{2} \mathrm{O}$ molecules, water sorption around them occurs on the basis of thermodynamics. Therefore, the $\mathrm{H}_{2} \mathrm{O}$ continuum moves along the DNA mono-strand, enveloping gradually the pairs of N-bases; dissolved nucleotides move together with water, destroy water envelopes, and replace them. This process continues up to the confluence of the $\mathrm{H}_{2} \mathrm{O}$ continuums moving towards each other from the different starting locations of DNA replication. During the process of replication, the water dipoles, entering between the DNA mono-strands of the daughter chromosome of the first generation, orient along each of them in such a way that the poles of the same polarity are directed to each of the newly-formed DNA double strands. Therefore, 
the outer facings of the $\mathrm{H}_{2} \mathrm{O}$-dipole layers surrounding each sister chromatids of the second generation have the same polarity. Thus, these chromosomes are affected by a repulsive electrostatic force, which unfolds them in a "double page" and pushes them apart as soon as the centromere-like region that has arisen between the sister chromatids of the second generation is replicated. The originated daughter chromosomes of the second generation move apart to the opposite walls of the cell. The replication cycle is finished.

The process of DNA replication proceeds for a rather long period, during which the segments consisting of two DNA double helixes and of one DNA double helix coexist along any one chromosome. In such a situation, there are no principal hindrances for simultaneous hydration of the segments of both types. Thus, replication of some segments of a newly-forming chromosome can start before complete replication of its parental chromosome. Evidently, the parental chromosome is somewhere multilayer and is increased in its cross-section; just this phenomenon makes the chromosomes sufficiently thick to be visible under optical microscopes.

The distinctions between eukaryotes and prokaryotes are essential and manifold; but, as was mentioned above, we think that the fundamental physicochemical regulations controlling the DNA replication and cell division for prokaryotes and eukaryotes are the same.

Thus, we described the hypothetical physicochemical mechanism of DNA replication and cell division for prokaryotes without notions on either enzymes or genetic code (therewith, we emphasize that we do not consider the chemical content of these processes). Note in this connection that an opinion that non-enzymatic replication is conceivable in a wide range of synthetic chemical systems was expressed in a number of works (e.g., Orgel, 1992, 2000).

Now we consider the principal peculiarities of the physicochemical mechanisms for the replication and cell-division cycles inherent in eukaryotic cells. Unlike the prokaryotic cells, the eukaryotic ones contain a chromosome family and each of the chromosomes has a linear (not circular) structure. Figure 6 presents the scheme of the eukaryotic cycle of chromosome replication for one pair of daughter chromosomes of the first generation, AC and BD (Fig. 6c); the capital letters A, B, C, D, F, G, and H under each of the DNA mono-strands individualize them and allow observation of their history. In this figure, we consider the chromosome region in the vicinity of the centromere. Figures $6 \mathrm{c}$ and $6 \mathrm{f}$ correspond to the start of replication cycle 1 in a mother cell, which is symbolized by one rectangle, and to the finish of this cycle in two daughter cells, which are symbolized by two rectangles, respectively. Figs. $6 \mathrm{a}$ and $6 \mathrm{~b}$ respond to the prehistory of these daughter chromosomes in the previous replication cycle 0 . Figs. $6 \mathrm{a}$ and $6 \mathrm{~d}$ and Figs. $6 \mathrm{~b}$ and $6 \mathrm{e}$ correspond to the DNA states after cytokinesis and after prophase, respectively. The physicochemical mechanism of replication for any eukaryotic chromosome consists in the processes of enveloping of the Nbases joining together the mono-strands in the DNA double helix, some unwinding of the DNA double helix, entering of waters and dissolved nucleotides into the capillaries thus formed, formation of a water continuum, "mooring" of the nucleotides to the corresponding sites at each of two DNA mono-strands, extrusion of water by the nucleotides, movement of the water continuum and dissolved nucleotides along the DNA double strand, and gradual duplication of each DNA mono-strand. The start of these processes is thermodynamically caused by a rather high $\mathrm{H}_{2} \mathrm{O}$ activity (i.e., by a rather high $\mathrm{H}_{2} \mathrm{O}$ concentration) in the cytoplasm; it occurs simultaneously at different chromosome locations (Sclafani \& Holzen, 2007; Kornberg \& Baker, 2005; Alberts et al., 2002) including two ends of the chromosome and induces no additional strain on the DNA double helix. For example, in Alberts et al. 
(2002), the following confirmation of this phenomenon for human chromosomes is given: "An average-sized human chromosome contains a single linear DNA molecule of about 150 million nucleotide pairs. To replicate such a DNA molecule from end to end with a single replication fork moving at a rate of 50 nucleotides per second would require $0.02 \cdot 150 \cdot 10^{6}=$ 3.0.106 seconds (about 800 hours). As expected, therefore, the autoradiographic experiments

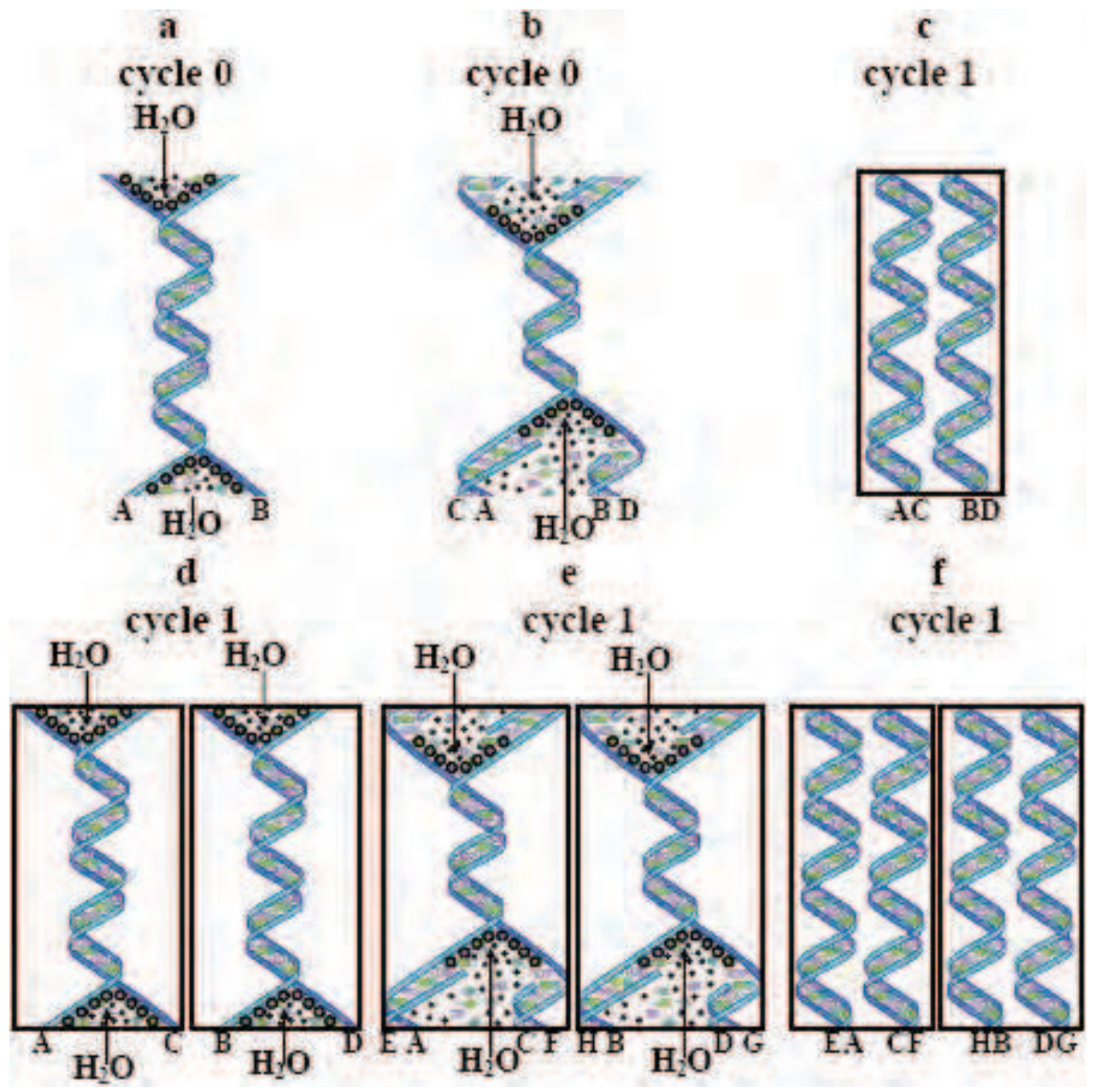

Fig. 6. Scheme of the DNA replication cycle in eukaryotic cells (in the centromere vicinity) (the letters A, B, C, D, E, F, G, and H under each of the DNA mono-strands individualize the DNA mono-strands): c-f: the replication cycle 1 ; c: start of replication cycle 1, late anaphase of cell cycle 1 , just after chromosome dissociation along the centromere; $\mathrm{d}$ : replication cycle 1, just after cytokinesis of cell cycle 1; e: replication cycle 1, late prophase of cell cycle 2; $\mathrm{f}$ : finish of replication cycle 1 , late anaphase of cell cycle 2 ; a: replication cycle 0 , just after cytokinesis of cell cycle 0 ; b: replication cycle 0 , late prophase of cell cycle 1 ; $\bullet$ is the water molecule, $2-, \mathbb{-},-$, , and $-\bowtie$ are different nucleotides; $\odot$ is the $\mathrm{H}_{2} \mathrm{O}$ envelope of an $\mathrm{N}$-base. 
... reveal that many forks are moving simultaneously on each eukaryotic chromosome." According to our views, the hydration and start of unwinding of chromosomes should proceed spontaneously and are in no want of extraneous support. Therefore, such enzymes as helicase and topoisomerase seem to be "jobless".

We consider some eukaryotic peculiarities on the basis of Fig. 7 showing schematically (not in proper scale) the chromosome sections II and III adjoining to one of the ends of the centromere I. Let A and B be the mono-strands of the chromosome under consideration. Water and nucleotides enter at the end of this chromosome between the DNA mono-strands (at the bottom of Fig. 7) and steadily move along them (in the upward direction in Fig. 7), unwinding the DNA double helix and duplicating each of the DNA mono-strands (in Fig. 7, the duplication of each of the mono-strands approaches to the boundary between the regions I and II). In the course of this process, nothing prevents duplication of the AC and BD double strands just formed; therefore, we believe that formation of new branches $\mathrm{HB}, \mathrm{DG}, \mathrm{FC}$, and $\mathrm{AE}$ should begin. Later, two DNA double helixes begin to form on the basis of each of these double strands. A similar pattern occurs at the other end of the chromosome under consideration. Thus, we are of opinion that each of the DNA double helixes in vivo has a "branchy" structure with a rather long bare (not branchy) "stem", the central region of which is the centromere, and with branchings located at either end of this stem. We are of opinion that just such a branchy structure of the DNA double helixes and water structuring around each of their elements increase the cross-sections of chromosomes in vivo and make them visible under light microscopes. Two opposite fronts of DNA double-helix duplication move steadily to the centromere and shorten the chromosome section that binds the sister chromatids.

This process proceeds for so long that the central section of the centromere has time to be covered with an organic protein-like layer hampering the final separation of the sister chromatids. However, the protein-like layer eventually dissolves; the moment of dissolution terminates the replication cycle.

It was mentioned that, according to the available data, DNA replication begins at its different locations simultaneously. Therefore, it may seem strange that the centromere region is located in the vicinity of the central section of the chromosome. The MRHhypothesis allows the following explanation of this phenomenon. The available light micrographs of living cells in early anaphase of mitosis (e.g., Davidson, 2004; Karkow, 2009) show that the central regions of chromosomes before their movement to the cell poles are located closely to each other, contrary to the end segments of these chromosomes, which are similar to two fans open widely on either side of the so-called mitotic spindle. Therefore, water and nucleotide diffusion to these central segments is hampered and their replication starts later than replication of the peripheral segments. Thus, it becomes clear why replication of the central segments terminates later than replication of the end segments.

Consider now the eukaryotic cell-division cycle, including mitosis. We consider the celldivision cycle as the time period between the moment right after cytokinesis in a cell cycle 0 (Fig. 6a) and the moment of cytokinesis in the following cell cycle 1 (Fig. 6d). The eukaryotic cell-division cycle differs fundamentally from the prokaryotic binary fission by the occurrence of a chromosome family instead of one chromosome, of a specific cell-cycle phase called interphase, and of a specific chromosome-family state termed chromatin and also by the formation of an envelope housing all newly-formed chromosomes within each newly-formed cell (the so-called nuclear envelope). Below, we describe the mechanism of the cell-division cycle, basing on the MRH-hypothesis. 


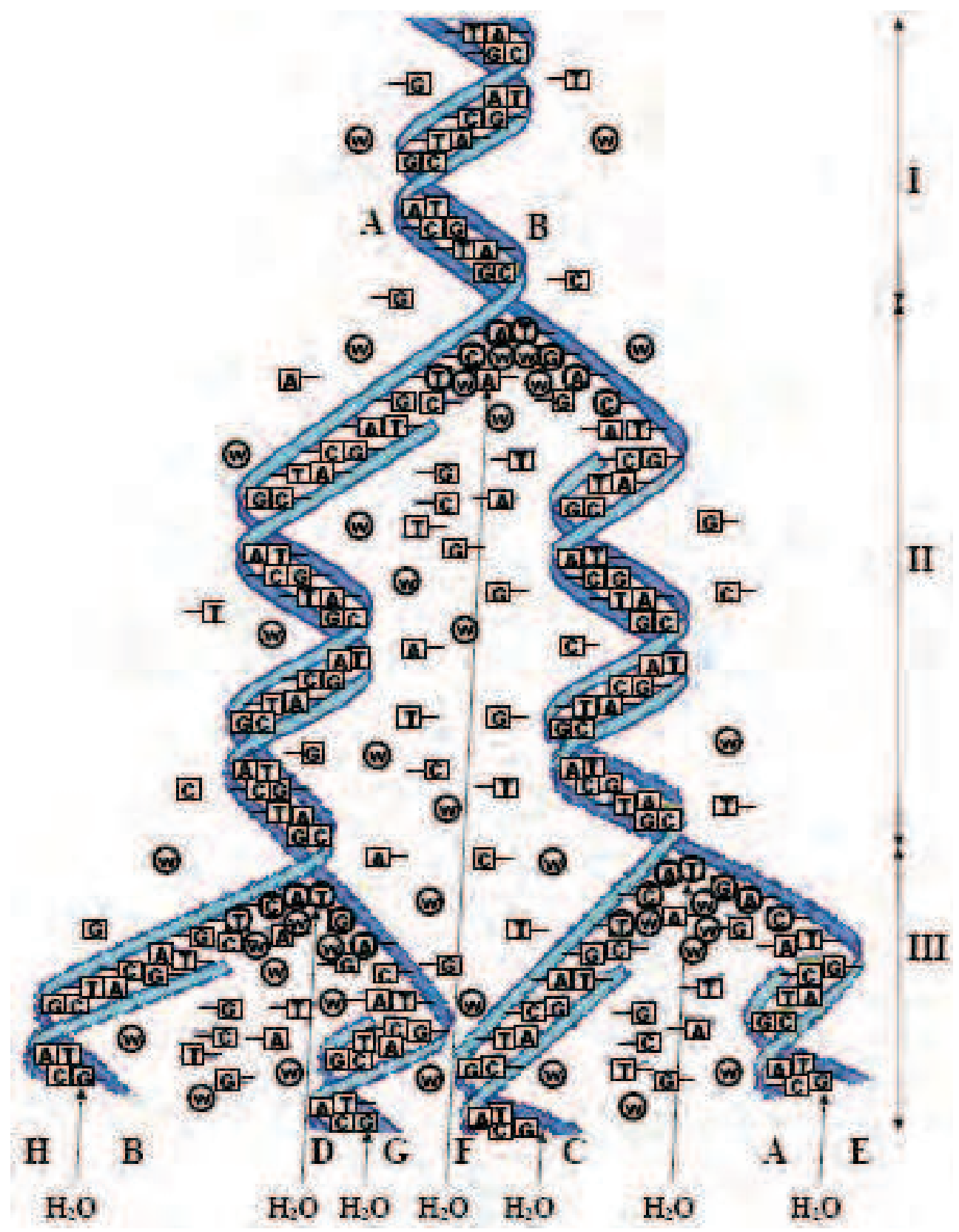

Fig. 7. Scheme of the "branchy" chromosome sections adjoining to one of the ends of the centromere: (1) are water molecules; for other denotations, see Fig. 6; II and III are the chromosome sections adjoining to one of the ends of centromere I. 
By the beginning of the prophase, the cytoplasm is enriched with organic substances and the chromosomes are concentrated within the nuclear envelope, their end segments being duplicated. During the prophase, the chromosomes sorb $\mathrm{H}_{2} \mathrm{O}$ and organic substances and become thicker as a result of formation of the hydrate-like structure inside double helixes, progressive duplication of their end segments, and branching. Active sorption of $\mathrm{H}_{2} \mathrm{O}$ by the chromosomes intensifies $\mathrm{H}_{2} \mathrm{O}$ diffusion into the cell from the outside, the $\mathrm{H}_{2} \mathrm{O}$ concentration in the cell increases, the cell and its nucleus grow, and the nuclear envelope begins to dissolve as a result of dilution of the cytoplasm by water.

The disappearance of the nuclear envelope and formation of the so-called mitotic plate can be explained as follows. During prometaphase and metaphase, the chromosomes continue to duplicate, the $\mathrm{H}_{2} \mathrm{O}$ concentration in the cell continues to increase, the nuclear envelope dissolves, the nucleus organics spill into the cell, the cytoplasm density in the equatorial plane of the cell decreases, and the chromosomes convene themselves in the zone of decreased density, forming the mitotic plate.

During anaphase, water continues to diffuse into the cell, the cytoplasm viscosity minimizes, chromosome replication along the centromere terminates, and each pair of sister chromatids dissociates into two daughter chromosomes moving apart to the opposite walls of the cell. Thus, two families of the newly-formed chromosomes arise. As was said above, the chromosomes are separated as a result of action of the electrostatic force induced by the $\mathrm{H}_{2} \mathrm{O}$-dipole layers surrounding each daughter chromosome. A number of authors (e.g., Alberts et al., 2002) hold the opinion that the daughter chromosomes move apart to the cell poles by the motors on microtubules; when a microtubule connects with the kinetochore, the motor activates, "crawls" up toward the centrosome, and the kinetochore provides separation of the sister chromatids. However, we think that this description is no more than one of the possible explanations of the observable phenomenon, because it is not clear how the microtubules learned to perform this complicated job. Besides, we refer to work (Reider et al., 2001), which claims that cells of different eukaryotic species can undergo mitosis (and interphase) without centrosomes (after their irradiation by laser); i.e., mitosis of eukaryotic cells can proceed normally without help of centrosomes. This work means that the causeeffect relation between the "motor" and movement of daughter chromosomes apart does not exist or it is opposite to the prevalent one. The prokaryotic binary fission proceeding with no developed organelles forces to be in earnest about this possibility. Apparently, the MRH-hypothesis allows simple and natural explanations for the process of separation of sister chromatids and for moving of the daughter chromosomes to the opposite cell poles.

During telophase and cytokinesis, chromosomes of each of two families are localized in opposite sides of the cell, are not connected to each other, and each chromosome sorbs water and nucleotides with minimal steric hindrances. As a result, two nuclei arise and the cell divides in two. Thus the cell cycle is complete.

In the course of telophase and cytokinesis of eukaryotic cells, a rather complicated hydrodynamic situation arises. Each family of chromosomes sucks in water from the center of the cell and from the region of the other family; in addition, $\mathrm{H}_{2} \mathrm{O}$ diffuses into the cell from the outside, the flows being different near the chromosome families and in the central region of the cell, because each chromosome family functions as a pump and, the closer the pump, the stronger the $\mathrm{H}_{2} \mathrm{O}$ diffusion flow; besides, the $\mathrm{H}_{2} \mathrm{O}$ concentrations and cytoplasm compositions differ among cells. Above, when considering the mechanism of the prokaryotic binary fission, we qualitatively explained the formation of the cleavage furrow and the subsequent cell division. However, it is known that three different situations are 
possible in living cells: (1) the above-described situation typical for prokaryotes; (2) the situation most abundant for eukaryotes, when cytokinesis and mitosis occur in conjunction, i.e., formation of two new nuclear envelopes and of the intracellular membrane separating two new nuclei proceeds almost simultaneously; and (3) the situation observable for a number of eukaryotes, when cytokinesis and mitosis occur separately and single cells with multiple nuclei exist for a rather long time.

Apparently, each of these situations can be clarified on the basis of consideration of a rather complicated hydrodynamic problem responding to cells filled with a semi-liquid substance, the density of which varies along the cell diameter. We think that formation of the nuclear envelopes and intracellular membranes should be explained by the same phenomena of sedimentation of organo-mineral substances from oversaturated aqueous solutions under conditions when chromosomes sorb $\mathrm{H}_{2} \mathrm{O}$ more rapidly than it diffuses into the cell from the outside. Analytical consideration of this problem is beyond this work; however, we think that all mentioned phenomena could be explained on the basis of such a physicochemical model. Evidently, the absence of nuclear envelopes in prokaryotic cells is caused by a rather high $\mathrm{H}_{2} \mathrm{O}$ concentration in the cytoplasm during mitosis and by the occurrence of only one parental chromosome in each cell. Namely, the rate of $\mathrm{H}_{2} \mathrm{O}$ sorption by each of the daughter prokaryotic chromosomes before binary fission is insufficient for formation of a region of oversaturated solution of organo-mineral substances around each of them. Meanwhile, the occurrence of nuclear envelopes in the cells of most species of eukaryotes is caused by a lower $\mathrm{H}_{2} \mathrm{O}$ concentration in the cytoplasm of dividing cells and by the occurrence of a family of chromosomes in each of them. Namely, the $\mathrm{H}_{2} \mathrm{O}$ flows directed to each of the chromosome families in a dividing eukaryotic cell are so intensive that they promote formation of regions of oversaturated solutions and precipitation of nuclear envelopes around each of the newly-formed chromosome families and subsequent formation of a similar region and precipitation of a membrane between the newly-formed nuclear envelopes. Thus, the phenomena observable in prokaryotic and eukaryotic cells can be understood on the basis of hydrodynamic considerations of the processes proceeding in aqueous solutions of organo-mineral substances whose concentrations vary near saturation conditions.

In this connection, we return to the idea that some organelles occurring in eukaryotic cells can be nothing but different organo-mineral crystals disappearing as a result of their swell and full dissolution or precipitating due to variations in the $\mathrm{H}_{2} \mathrm{O}$ concentration in the cytoplasm. The occurrence of only primitive organelles in the cells of some prokaryotic species (Kerfeld et al., 2005) or the absence of organelles in the cells of other prokaryotic species can be, apparently, explained by the poorness of the organic composition of the prokaryotic cytoplasm and by a high $\mathrm{H}_{2} \mathrm{O}$ concentration in it. As for such organelles as mitochondria and chloroplasts, which "live" inside eukaryotic cells and have their own DNA, their metabolism is evidently controlled by the regularities resembling those inherent in prokaryotic cells.

\section{Conclusion}

This chapter represents an attempt to understand the physicochemical grounds of DNA replication. Moreover, it is the first attempt to understand the processes of living matter origination and subsequent development and reproduction on the basis of one common natural phenomenon. This phenomenon is hydrate formation and destruction. Its 
physicochemical content is known in detail. The unique feature of this phenomenon, occurring within limited ranges of natural conditions, consists in the following. It is capable of supporting the process of chemical formation of germs of some substances with the definite sizes and very similar but identical chemical compositions and of supporting subsequent copying of these germs on the basis of diffusion of some source substances and water from outside into the system. The unique features of the hydrate phase as such consist in the facts that it is honeycomb, it is composed of the $\mathrm{H}_{2} \mathrm{O}$-matrix and intra-matrix guest substances, and its formation and destruction is thermodynamically supported and depends on the $\mathrm{H}_{2} \mathrm{O}$ content in the system. Therefore, if $\mathrm{H}_{2} \mathrm{O}$ and source substances enter the system and the guest products (chemically formed within the structural cavities) come off, the hydrate structure is capable of repeated formation and destruction with desorption of the same product.

The LOH-hypothesis differs principally from all living matter origination hypotheses previously published. These differences are not only factual but also represent an original world outlook and original philosophy. We consider the life origination process as a system of thermodynamically caused regular and inevitable chemical transformations, which are regulated by universal physical and chemical laws. We assume that living matter originated repeatedly in different localizations, and that each of them could give rise to a multitude of different living organisms. Different organisms consist of the cells that are similar in their constitution because they are built by Nature on the basis of the same mineral materials and the same physical and chemical laws.

Not proteins and not amino-acids, but the DNA and RNA molecules are the first carriers of life. Living matter originated and can originate now everywhere, where necessary minerals and necessary ambient conditions exist for long periods of time.

Our hypothesis includes an important notion on a "thermodynamic front", the temporal movement of which determines the gradual slow filling of the gas-hydrate cavities, step-bystep formation of almost the same N-bases and the same riboses within the cavities, and subsequent gradual and slow (on human life duration scale) growth and thermodynamic regularization of the DNA- and RNA-like molecules.

We also kept in mind the notion on the occurrence of a "thermodynamic front" when formulating the MRH-hypothesis. In our opinion, the same natural phenomenon of formation-destruction of hydrate structures underlies the living-matter origination and replication. However, the base lines of these two fronts pass on different levels of complexity of the source substances; if origination of the primary DNAs proceeded on the basis of simple minerals of an inorganic nature inside the matrix that contained initially only methane, replication of the DNAs in our days proceeds, in each case, on the basis of a definite primary DNA and on the basis of nutrients, which represent more complicated constructive parts. At that, just the effects of the "thermodynamic front" and of the hydrate matrix geometry create the conditions when, in the immediate vicinity of the maternal DNA mono-strand, only the mono-strand identical in its chemical composition and structure to the one that was paired with the maternal DNA mono-strand before the replication start can be formed. (The occurrence of the last effect should be verified by computer simulation.) With time and as a result of the natural selection, many of the DNAs adapted themselves to more complicated nutrients and higher temperatures as compared with those available to their archaean ancestry and their inter-replication periods became much shorter. Therewith, they learned to use only the necessary components of the nutrients for their replication, to preserve the surpluses in the form of proteins, and to throw out unusable remains. It goes 
without saying, the process of DNA replication is thermodynamically caused, similarly to the process of origination of the primary DNAs.

Before finishing this chapter, we consider necessary to formulate our principal opinion on the place of the so-called enzymes (and co-enzymes) in the cellular metabolism. In corpore consideration of the theme of enzymes is a special aim. However, we mentioned above some enzymes that, in the framework of our considerations, seem to be jobless and, therefore, we can not leave this theme without attention. Essentially, the today widely-distributed views on the intra-cellular processes connive at the occurrence of several lines of chemical interactions within each living cell. Those are, at least, interactions between DNA, enzymes, and co-enzymes; therewith, the objects of these interactions are divided in space, their chemical interactions are synchronized in time, and they diffuse to each other at a strictly determined moments, react, and go off. Up to now, no physical phenomenon that could determine these processes was proposed. Thus, all they were considered as random ones. However, the probability of the regular situations of such a kind is extremely low. In addition, many hundreds, and even thousands, of enzymes are housed within each cell and each of them is obliged to rub against DNA and to jump off giving place to another one; and all these events should proceed in a rather viscous medium characterized by a low rate of diffusion. It is quite possible that the formation-destruction of hydrate structures is just the phenomenon that is capable of providing the replication process and that the so-called enzymes or, at least, most of them are really nothing more than the initial surpluses and remains before their consolidation. Being out of living matter, some of them may be capable of catalyzing definite chemical processes under definite conditions.

The LOH-hypothesis allows for the living-world variety explanation from naturalistic positions. Each methane-niter-phosphate "incubator" yielded a great number of DNA- and RNA-like molecules close in their principal compositions but different in the sequences of the different N-bases. A great number of such "incubators" could exist during different periods at different sites of the Earth. Their occurrence on other planets cannot be excluded.

\section{References}

Alberts, B.; Johnson, A.; Lewis, J.; Raff, M.; Roberts, K. \& Walter, P. (2002). Molecular Biology of the Cell (4th ed), Garland Science, Oxford, UK.

Alberty, R.A. (2003). Thermodynamics of Biochemical Reactions, Wiley, Hoboken, NJ, USA.

Arnott, S.; Wilkins, M.H.F.; Hamilton, L.D. \& Langridge R. (1965). Fourier Synthesis Studies of Lithium DNA: Part III: Hoogsteen Models. J.Mol.Biol., Vol. 11, No. 2, pp. 391-402.

Atwood, J.L. et al. (eds) (1996). Comprehensive Supramolecular Chemistry. Pergamon Press, N.Y., USA.

Blyumenfeld, L.A. (1996). Information, Thermodynamics, and the Structural Principles of Biological Systems. Soros's Educat. J., No.7, pp. 88-92.

Blyumenfeld, L.A. (1981). Problems of Biological Physics, Springer-Verlag, Berlin.

Blyumenfeld, L.A. (2002). Solvable and Unsolvable Problems of BiologicalPhysics, Ch. 6. Editorial URSS, Moscow.

Boerio-Goates, J. (2005). Private communication.

Buss, L.W. (1987). The Evolution of Individuality, Princeton Univ. Press., Princeton, USA. 
Byk, S.Sh. \& Fomina, V.I. (1970). Gas Hydrates. In: Progress in Science and Technology. Ser. Chemistry. Physical Chemistry, 1968, VINITI, Moscow, Russia.

Carroll, J.J. (2003). Natural Gas Hydrates: A Guide for Engineers Amsterdam, Gulf Professional Publ., Amsterdam, Netherlands.

Chaplin, M. (2010). Water Structure and Science. http://www.lsbu.ac.uk/water/clathrat2.html; last updated 5 July 2010.

Clarke, E.C., Ford, R.W. \& Glew, D.N., Propylene Gas Hydrate Stability. Can. J. Chem., 1964, vol. 42, pp. 2027-2029.

Cech, T.R. \& Bass, B.L. (1986). Biological Catalysis by RNA. Annu. Rev. Biochem., Vol. 55, pp. 599-629.

Crick, F.H.C. \& Watson, J.D. (1954). The Complementary Structure of Deoxyribonucleic Acid. Proc. Roy. Soc. Lond. A, Vol. 223, pp. 80-96.

Davidson D.W., Garg S.K., Gough S.R., Handa Y.P., Lawson W.F. et al. (1986). Laboratory Analysis of a Naturally Occurring Gas Hydrate from Sediment of the Gulf of Mexico, Geochim. Cosmochim. Acta., V. 50. № 4. pp. 619-623.

Davidson, M.W. (2004). http:/ / micro.magnet.fsu.edu/gallery/mitosis/earlyanaphase.html

Day, J.C. \& Robb, I.D. (1981). Thermodynamic Parameters of Polyacrylamides in Water. Polymer, Vol. 22., No. 11, pp. 1530-1533.

Deamer, D.W. (1997). The First Living Systems: a Bioenergetic Perspective. Microbiol. Mol. Biol. Rev., Vol. 61, No. 2, pp. 239-261.

Drew, H.; Takano, T.; Tanaka, S.; Itakura, K. \& Dickerson, R. (1980). High-Salt d(CpGpCpG), a Left-Handed Z' DNA Double Helix. Nature, Vol. 286, No. 5773, pp. 567-573.

Fedo, C.M. \& Whitehouse, M.J. (2002). Metasomatic Origin of Quartz-Pyroxene Rock, Akilia, Greenland, and Implications for Earth's Earliest Life. Science, Vol.296, pp.1448-1452.

Fedonkin, M.A. (2009). Eukaryotization of the Early Biosphere: a Biogeochemical Aspect. Geochem. Intern., Vol. 47, No. 13, pp. 1265-1333.

Fedonkin, M.A. (2006). Two Chronicles of Living Matter. In: Problems of geology and mineralogy, (A.M. Pystin, ed.), Geoprint, Syktyvkar, pp. 331-350.

Feughelman, M.; Langridge, R.; Seeds, W.E.; Stokes, A.R.; Wilson, H.R.; Hooper, C.W.; Wilkins, M.H.F.; Barclay, R.K. \& Hamilton, L.D. (1955). Molecular Structure of Deoxyribose Nucleic Acid \& Nucleoprotein. Nature, Vol.175, No. 4463, pp. 834-838.

Flory, P.J. ( 1962). On the Morphology of the Crystalline State in Polymers. J. Am. Chem. Soc., Vol. 84, No.15, pp. 2857-2867.

Galimov, E.M. (2001). Phenomenon of Life, Editorial URSS, Moscow, Russia.

Galimov, E.M. (2009). Concept of Sustained Ordering and ATP-related Mechanism of Life's Origin. Int. J. Mol. Sci., Vol. 10., No. 5, pp. 2019-2030.

Ginsburg, G.D. \& Soloviev, V.A. (1998). Submarine Gas Hydrates, Okeanologia, St. Petersburg, Russia, 220 p.

Ginzburg, V.L. (1999). What Problems of Physics and Astrophysics Seem Now to Be Especially Important and Interesting (Thirty Years Later, Already on the Verge of XXI Century)? Physics-Uspekhi (Adv. Physical Sciences), Vol. 42, No. 4, pp. 353-373.

Ginzburg, V.L. (2004). On Superconductivity and Superfluidity (What I Have and Have not Managed to Do), as Well as on the 'Physical Minimum' at the Beginning of the XXI Century. Physics-Uspekhi (Adv. Physical Sciences), Vol. 47, No. 11, pp. 1155-1170. 
Gostev, B.V. \& Ostrovskii, V.E. (1993). Calorimetric and Sorption Study of Water Sorption by Perfluorinated Membrane Materials. Russ. J. Phys. Chem., Vol. 67, pp. 1255-1262.

Gostev, B.V. \& Ostrovskii, V. (1994). Water Sorption by Perfluorinated Membrane Materials Treated by Ferric Chloride Water Solution. Russ. J. Phys. Chem. Vol. 68, pp. 668-675.

Hagan, M.M. (1962). Clathrate Inclusion Compounds. Reinhold Publ. Corp., New York, USA.

Hedges, S.B. \& Kumar, S. (2003). Genomic Clocks and Evolutionary Timescales. Trends in Genetics, Vol. 19, No. 4, pp. 200-206.

Henze, K. E Martin, W. (2003). Evolutionary Biology: Essence of Mitochondria. Nature, Vol. 426, pp. 127-128.

Jordan, T.H. \& Mac, T.C. (1967). Polyhedral Clathrate Hydrates. XII. The Structure of $\left(\mathrm{CH}_{3} \mathrm{CH}_{2}\right)_{2} \mathrm{NH} \cdot 8^{2} / 3 \mathrm{H}_{2} \mathrm{O}$. J. Chem. Phys., Vol. 47, No. 4, pp. 1222-1228.

Josse, J.; Kaiser, A.D. \& Kornberg, A. (1961). Enzymatic Synthesis of Deoxyribonucleic Acid: VIII. Frequencies of Nearest Neighbor Base Sequences in Deoxyribonucleic Acid. J. Biol. Chem., Vol. 236, pp. 864-875.

Kadyshevich, E.A. (2006). Mitosis: Does It Proceed According to an Enclosed Code or to Deterministic Physicochemical Regulations? In: Abstracts of the XIVth ISBC Conference, p. 49, Univ. Gdansk, Gdynia, Poland.

Kadyshevich, E.A (2007). Generalized Hydrate Hypothesis of Origin of Nucleic Acids and Hydrocarbons in Nature: Whether It Opens a New Page in Laboratory Syntheses of Biomaterials, In: Adv. in Petrochem. Polymers, Proc., BB 1-4, Bangkok, Thailand.

Kadyshevich E.A. (2009a). The PFO-CFO Hypothesis of Planet Formation. Meteorit.E Planet. Sci., Vol. 44, pp. A105.

Kadyshevich E.A. (2009b). The Planet Formation Hypothesis: Why Are the Solar System Planets Different in their Chemical Compositions? EPSC Abstr., Vol. 4, EPSC2009-1.

Kadyshevich, E.A \& Ostrovskii, V.E. (2007). Hypothetical Physicochemical Mechanisms of Some Intracellular Processes: The Hydrate Hypothesis of Mitosis and DNA Replication. Thermochim. Acta, Vol. 458, No. 1-2. pp. 148-161.

Kadyshevich, E.A \& Ostrovskii, V.E. (2009). Hydrate Hypothesis of Living Matter Origination (LOH-Hypothesis): Thermodynamic Grounds of Formation of Living Matter Simplest Elements from Hydrocarbons and Niter. J. Therm. Anal. Calor., Vol. 95, No. 2, pp. 571-578.

Kadyshevich, E.A \& Ostrovskii, V.E. (2010a). Oxygen Isotopic Anomalies in the Rocks of Celestial Objects: Are They the Key to the Planet Formation Mechanism? EPSC Abstracts, Vol. 5, EPSC2010-3.

Kadyshevich, E.A \& Ostrovskii, V.E. (2010b). Development of the PFO-CFO Hypothesis of Solar System Formation: Why Do the Celestial Objects Have Different Isotopic Ratios for Some Chemical Elements? Proc. Int. Aston. Union, Vol. 6, No. S274 (Advances in Plasma Astrophysics), pp. 95-101, Cambridge Univ. Press, UK.

Kadyshevich, E.A \& Ostrovskii, V.E. (2010c). Hydrate Hypothesis of Living Matter Origination: Logical and Thermodynamic Grounds. In: Degassing of the Earth: geotectonics, geodynamics, geofluids, oils, gases, hydrocarbons, and life. pp. 195-198, GEOS, Moscow, Russia. 
Kadyshevich, E.A \& Ostrovskii, V.E. (2010d). Life Origination Hydrate Hypothesis (LOHHypothesis): What Questions Can Be Hypothetically Answered at Present? EPSC Abstracts, Vol. 5, EPSC2010-5.

Kant, I. (1997). Critique of Practical Reason, Cambridge Univ. Press, Cambridge (Transl. into English from "Kritik der praktischen Vernunft", P. Reclam 1878, Leipzig, Germany.

Kargin, V.A. (1962). Modern Problems of Polymer Science. Moscow State Univ., Moscow, Russia.

Karkow, B. (2009). HAPS Histology Image Database.

Kauffman, S. (1993). The Origin of Order Self Organization and Selection in Evolution, Oxford Univ. Press., Oxford, UK.

Kerfeld, C.A.; Sawaya, M.R.; Tanaka, S.; Nguyen, C.V.; Phillips, M.; Beeby, M. \& Yeates, T.O. (2005). Protein Structures Forming the Shell of Primitive Bacterial Organelles. Science, Vol. 309, pp. 936-938.

Konovalov, M.I. (1893). Nitrating Action of Dilute Nitrous Acid at Hydrocarbons of Saturated Character, Moscow, Russia.

Kornberg, A. \& Baker, T.A. (2005). DNA Replication. 2nd. ed. Paperback Ed., p. 472, ISBN 978-1-891389-44-3, $932 \mathrm{p}$.

Lodish, H.; Berk, A.; Zipursky, L.; Matsudaira, P.; Baltimore, D. \& Darnell, J. (2000). Molecular Cell Biology (4th ed.) W.H. Freeman, New-York, USA.

Li, T. \& Nicolaou, K.C. (1994). Chemical Self-Replication of Palindromic Duplex DNA. Nature, Vol. 369, pp. 218-221.

Lide D.R. (ed.) (1996). Handbook of Chemistry and Physics (76th ed.), CRC Press, London, UK.

MacDonald I.R., Guinasso N.L., Brooks J.M., et al. (1994). Seafloor Gas-Hydrates: Video Documenting Oceanographic Influences on Their Formation and Dissociation. In: Near Surface Expression of Hydrocarbon Migration. AAPG Hedberg Res. Conf. Abstracts, Vancouver, B.C., Canada.

McMullan, R. K.; Jordan, T. H. \& Jeffrey, G. A. (1967). Polyhedral Clathrate Hydrates. XII. The Crystallographic Data on Hydrates of Ethylamine, Dimethylamine, Trimethylamine, n-Propylamine (Two Forms), Iso-Propylamine, Diethylamine (Two Forms), and Tert-Butylamine. J. Chem. Phys., Vol. 47, No. 4, pp. 1218-1223.

Menor-Salván, C.; Ruiz-Bermejo, M.; Osuna-Esteban, S. \& Veintemillas-Verdaguer S. (2009). Efficient Synthesis of Pyrimidines and Triazines from Urea and Methane in Ice Matrix. Orig. Life Evol. Biosph., Vol. 39, No. SI, pp. 250-251.

Milkov, A.V. (2004). Global Estimates of Hydrate-Bound Gas in Marine Sediments: How Much Is Really out There? Earth-Sci Rev., Vol. 66, No. 3-4, pp. 183-197.

Mojzsis, S.J.; Arrhenius, G.; McKeegan, K.D.; Harrison, T.M.; Nutman, A.P. \& Friend, C.R.L. (1996). Evidence for Life on Earth before 3,800 Million Years Ago. Nature, Vol. 384, pp. 55-59.

Newton, I. (1687). Philosophiñ Naturalis Principia Mathematica, Jussu Soc. Regiñ ac Typis Josephi Streater, Londini; [Translated into English: Mathematical Principles of Natural Philosophy, Univ. of California Press, Berkeley, Calif., 1999].

Oborin, A.A. \& Khmurchik, V.T. (2008). Chemosynthesis at Deep Fluids as an Additional Source of Organic Matter in the Lithosphere. In: Degassing of the Earth; geodynamics, geofluids, oil, gas, and their parageneses, pp. 366-367. GEOS, Moscow, Russia. 
Oparin, A.I. (1924). The Origin of Life. Moscow Worker publisher, Moscow, Russia, 71 p.

Oparin, A.I. (1957). The Origin of Life on Earth (3rd ed.). Acad. Press Inc., N.Y., USA 459 p.

Orgel, L.E. (2000). Self-Organizing Biochemical Cycles. Proc. Nat. Acad. Sci., Vol. 97, No. 28, pp. 12503-12507.

Orgel, L.E. (1992). Molecular Replication. Nature, Vol. 358, pp. 203-209.

Ostrovskii, V.E. (2002). Differential Microcalorimeter for Isothermal Measurements of Heat Effects in Two-Phase Systems and Examples of Its Application. Rev. Sci. Instr., Vol. 73, pp. 1304-1312.

Ostrovskii, V.E. (2010). Hypothesis of the Natural Gas Abiotic Origin in the Context of Living Matter Origination. In: Gas Chemistry at the Present Stage of Development (eds. A.I. Vladimirov, A.L. Lapidus), Gubkin RSU NG, pp. 35-69, Moscow, Russia.

Ostrovskii V.E.; Tsurkova B.V.; Kadyshevich E.A. \& Gostev B.V. (2000). Differential Heat Effects, Kinetics, and Mechanisms for the Drying and Water Vapor Wetting of the Acrylamide-Water System. Russ.J. Phys. Chem., Vol. 74, No. 2, pp. 191-201.

Ostrovskii, V.E.; Tsurkova, B.V.; Kadyshevich E.A. \& Gostev B.V. (2001). Comparison Study of the Acrylamide-Water and Polyacrylamide-Water Systems: Differential Heat Effects, Kinetics, and Mechanisms of Drying and Vapor-Phase Wetting. J. Phys. Chem. B, Vol. 105, No. 50, pp. 12680-12687.

Ostrovskii, V.E. \& Gostev, B.V. (1996). Heat Effects and Rates and Molecular Mechanisms of Water Sorption by Perfluorinated Polymer Materials Bearing Functional Groups. J. Therm. Anal., Vol. 46. pp. 397-416.

Ostrovskii, V.E. \& Kadyshevich, E.A. (2000). Use of Data on the Polyacrylamide-Water System in Analyzing the Equilibrium DNA-Water Structure. Russ. J. Phys. Chem., Vol. 74, No. 7, pp. 1114-1124.

Ostrovskii, V.E. \& Kadyshevich, E.A. (2002). Hydrate Model of the Equilibrium DNA- $\mathrm{H}_{2} \mathrm{O}$ System. Intern. J. Nanosci., Vol. 1, No. 2. pp. 101-121.

Ostrovskii, V.E. \& Kadyshevich, E.A. (2006). Thermodynamics of Formation of Nitrogen Bases and D-ribose from Mineral Substances in Light of the Problem of Origination of Simplest Elements of Living Matter. Thermochim. Acta, Vol. 441, No. 1, pp. 69-78.

Ostrovskii, V.E. \& Kadyshevich, E.A. (2007). Generalized Hypothesis of the Origin of the Living-Matter Simplest Elements, Transformation of the Archean Atmosphere, and the Formation of Methane-Hydrate Deposits. Physics-Uspekhi (Advances in Physical Sciences), Vol. 50, No. 2, pp. 175-196.

Ostrovskii, V.E. \& Kadyshevich, E.A. (2008). Hypotheses of Hydrocarbon-Hydrate Formation and Living Matter Origination at the Earth. In: Degassing of the Earth; geodynamics, geofluids, oil, gas, their parageneses, pp. 374-377, GEOS, Moscow, Russia.

Ostrovskii, V.E. \& Kadyshevich, E.A. (2009a). Hypothesis of Formation of Planets from Nebula: Why Are the Planets Different in Their Chemical Compositions? Orig. Life. Evol. Biosp., Vol. 39, No. SI, pp. 217-219.

Ostrovskii, V.E. \& Kadyshevich, E.A. (2009b). Solar System Formation Hypothesis: Why the Chemical Compositions of the Planets Are so Different? Geochim. Cosmochim. Acta, Vol. 73, pp. A 979.

Ostrovskii, V.E. \& Kadyshevich, E.A. (2009c). Life Origination Hydrate Hypothesis (LOHHypothesis). Orig. Life. Evol. Biosp., Vol. 39, No.SI, pp. 219-220. 
Ostrovskii, V.E. \& Kadyshevich, E.A. (2010). Life origination hydrate hypothesis (LOHhypothesis): the content and chemical and thermodynamic grounds. In: Chemical Evolution E Origin of Life, Intern. Workshop Proc., pp. 1-2, Jain Print., Roorkee, India.

Ostrovskii, V.E. \& Kadyshevich, E.A. (2011). Physicochemical model of formation of the Solar System planets: the causes of differences in the chemical composition of planets. In: "Physchemistry-2010", Selected works (ed. A.S. Smolyanskii), LLC "Rosinatal", pp. 46-61, Obninsk, Russia.

Ostrovskii, V.E. \& Tsurkova, B.V. (1997). Differential Heat Effects and Mechanisms of Interaction of Polyacrylamide with Water, Russ. J. Phys. Chem., Vol. 71, pp. 967-973.

Ostrovskii. V.E., \& Tsurkova, B.V. (1998a). The System Polyacrylamide-Water. Differential Heat Effects, Rates and Molecular Mechanisms of Wetting and Drying. J. Therm. Anal., Vol. 51. pp. 369-381.

Ostrovskii, V.E. \& Tsurkova, B.V. (1998b). The Polyacrylamide-Water System: Application of Differential Calorimetry to Study the Mechanisms of Dissolution. Thermochim. Acta, Vol. 316. pp. 111-122.

Ould-Moulaye, C.B.; Dussap C.G. \& Gros J.B. (2001). A Consistent Set of Formation Properties of Nucleic Acid Compounds. Purines and pPyrimidines in the Solid State and in Aqueous Solution. Thermochim. Acta, Vol. 375. No. 1-2. pp. 93-107.

Parmon, V.N. (1999). Abiogenic Catalysts in Nature. Col. Surf. A, Physicochem. Eng. Aspects, Vol. 151, pp. 351-365.

Pauling, L. (1970). General Chemistry (3rd ed.), W.H. Free man, San Francisco, USA.

Platteeuw, J.C. \& Van-der-Waals, J.H. (1959). Thermodynamic Properties of Gas Hydrates II: Phase Equilibria in the System $\mathrm{H}_{2} \mathrm{~S}-\mathrm{C}_{3} \mathrm{H}_{8}-\mathrm{H}_{2} \mathrm{O}$ at $-3^{\circ} \mathrm{C}$, Rec. Trav. Chim., Vol. 78, No. 2, pp. 126-133.

Pinder, K.L. (1964). Time Dependent Rheology of the Tetrahydrofuran-Hydrogen Sulphide Gas Hydrate Slurry. Can. J. Chem. Eng., Vol. 42, No. 3, pp. 132-138.

Pinder, K.L. ( 1965). A Kinetic Study of the Formation of the Tetrahydrofuran Gas Hydrate. Can. J. Chem. Eng., Vol. 43, No. 5, pp. 271-274.

Reider, C.L.; Faruki, S. \& Khodjakov, A. (2001). The Centrosome in Vertebrates: More than a Microtubule-Organizing Center. Trends in Cell Biology, Vol. 11, No. 10, pp. 413-419.

Rhodes, D. \& Klug, A. (1980). Helical Periodicity of DNA Determined by Enzyme Digestion. Nature, Vol. 286, No. 5773, pp. 573-578.

Schippers, A.; Neretin, L.N.; Kallmeyer, J. et al. (2005). Prokaryotic Cells of the Deep Subseafloor Biosphere Identified as Living Bacteria. Nature, Vol. 433. pp. 861-864.

Sclafani, R.A. \& Holzen, T.M. (2007). Cell Cycle Regulation of DNA Replication. Annu. Rev. Genet., Vol. 41, pp. 237-280.

Segré, D.; Pilpel, Y. \& Lancet, D. (1998). Mutual Catalysis in Sets of Prebiotic Organic Molecules: Evolution through Computer Simulated Chemical Kinetics. Physica A (Amsterdam), Vol. 249, pp. 558-564.

Shapiro, R. (2000). A Replicator Was not Involved in the Origin of Life. IUBMB Life, Vol. 49, pp. 173-176.

Shapiro, R. (2006). Small Molecule Interactions Were Central to the Origin of Life. The Quart. Review of Biology, Vol. 81, pp. 105-125. 
Silberberg, A; Eliassaf, J. \& Katchalsky, A. (1957). Temperature-Dependence of Light Scattering and Intrinsic Viscosity of Hydrogen Bonding Polymers. J. Polym. Sci., Vol. 23, No. 103, pp. 259-284.

Spirin, A.S. (2001). Protein Biosynthesis, the RNA World, and the Origin of Life. Herald of the Russian Academy of Sciences, Vol. 71, No. 2, pp. 146-153.

Stackelberg, M. \& Muller, H. (1954). Solid Gas-Hydrate II. Structure and Stereochemistry. Z. Electrochem., Vol. 58, No. 1, pp. 25-39.

Stackelberg, M. \& Meuthen, B. (1958). Solid Gas-Hydrate VII. Water-Soluble Ether. Z. Electrochem., Vol. 62, pp. 130-131.

Thompson, H.B. \& LaPlanche, L.A. (1963). Electric Moments of N,N-disubstituted Amides. J. Phys. Chem., Vol. 67, No. 10, pp. 2230-2231.

Tresher. J.; Durckworth, R. \& Williams, A. (1992). The Identification of Three New Seepage Sites in the Gulf of Mexico, Shallow Gas Group News Letters, № 6.

Van-der-Waals, J.H. \& Platteeuw, J.C. (1959) Clathrate Solutions. Adv. Chem. Phys., Vol. 2, pp. 1-57.

van Zuilen, M.A.; Lepland, A. \& Arrhenius, G. (2002). Reassessing the Evidence for the Earliest Traces of Life. Nature, Vol. 418, pp. 627-630.

Wang, J.C. (1979). Helical Repeat of DNA in Solution. Proc. Natl. Acad. Sci. USA, Vol. 76, No. 1, pp. 200-203.

Watson, J.D. \& Crick, F.H.C. (1953). Molecular Structure of Nucleic Acids: A Structure for Deoxyribose Nucleic Acid. Nature, Vol. 171, No. 4356, pp. 737-738.

Wilkins, M.H.F.; Stokes, A.R. \& Wilson, H.B. (1953). Molecular Structure of Nucleic Acids: Molecular Structure of Deoxypentose Nucleic Acids. Nature, Vol. 171, No. 4356, pp. 738-740.

Wilkins, M.H.F. (1961). The Molecular Structure of DNA. J. Chim. Phys., Vol. 58, pp. 891-898.

Zielinski, W.S. \& Orgel, L.E. (1987). Autocatalytic Synthesis of a Tetranucleotide Analogue. Nature, Vol. 327, No. 6120, pp. 346-347.

Zimmerman, S.B. \& Pheiffer, B.H. (1979). Helical Parameters of DNA Do not Change when DNA Fibers Are Wetted: X-ray Diffraction Study. Proc. Natl. Acad. Sci. USA., Vol. 76, No. 6, pp. 2703-2707. 


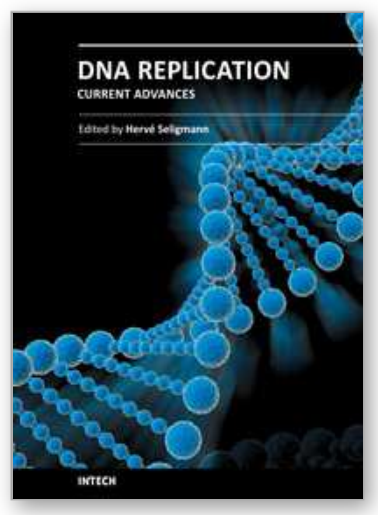

\section{DNA Replication-Current Advances}

Edited by Dr Herve Seligmann

ISBN 978-953-307-593-8

Hard cover, 694 pages

Publisher InTech

Published online 01, August, 2011

Published in print edition August, 2011

The study of DNA advanced human knowledge in a way comparable to the major theories in physics, surpassed only by discoveries such as fire or the number zero. However, it also created conceptual shortcuts, beliefs and misunderstandings that obscure the natural phenomena, hindering its better understanding. The deep conviction that no human knowledge is perfect, but only perfectible, should function as a fair safeguard against scientific dogmatism and enable open discussion. With this aim, this book will offer to its readers 30 chapters on current trends in the field of DNA replication. As several contributions in this book show, the study of DNA will continue for a while to be a leading front of scientific activities.

\section{How to reference}

In order to correctly reference this scholarly work, feel free to copy and paste the following:

Ostrovskii Victor E. and Kadyshevich Elena A. (2011). Mitosis and DNA Replication and Life Origination Hydrate Hypotheses: Common Physical and Chemical Grounds, DNA Replication-Current Advances, Dr Herve Seligmann (Ed.), ISBN: 978-953-307-593-8, InTech, Available from: http://www.intechopen.com/books/dnareplication-current-advances/mitosis-and-dna-replication-and-life-origination-hydrate-hypotheses-commonphysical-and-chemical-gro

\section{INTECH}

open science | open minds

\section{InTech Europe}

University Campus STeP Ri Slavka Krautzeka 83/A

51000 Rijeka, Croatia Phone: +385 (51) 770447

Fax: +385 (51) 686166

www.intechopen.com

\section{InTech China}

Unit 405, Office Block, Hotel Equatorial Shanghai

No.65, Yan An Road (West), Shanghai, 200040, China

中国上海市延安西路65号上海国际贵都大饭店办公楼 405 单元

Phone: +86-21-62489820

Fax: +86-21-62489821 
(C) 2011 The Author(s). Licensee IntechOpen. This chapter is distributed under the terms of the Creative Commons Attribution-NonCommercialShareAlike-3.0 License, which permits use, distribution and reproduction for non-commercial purposes, provided the original is properly cited and derivative works building on this content are distributed under the same license. 